Document downloaded from:

http://hdl.handle.net/10251/102694

This paper must be cited as:

Moliner Marin, M.; Willhammar, T.; Wan, W.; González, J.; Rey Garcia, F.; Jorda Moret, JL.; Zou, X.... (2012). Synthesis design and structure of a multipore zeolite with interconnected 12- and 10-MR channels. Journal of the American Chemical Society. 134(14):6473-6478. doi:10.1021/ja301082n

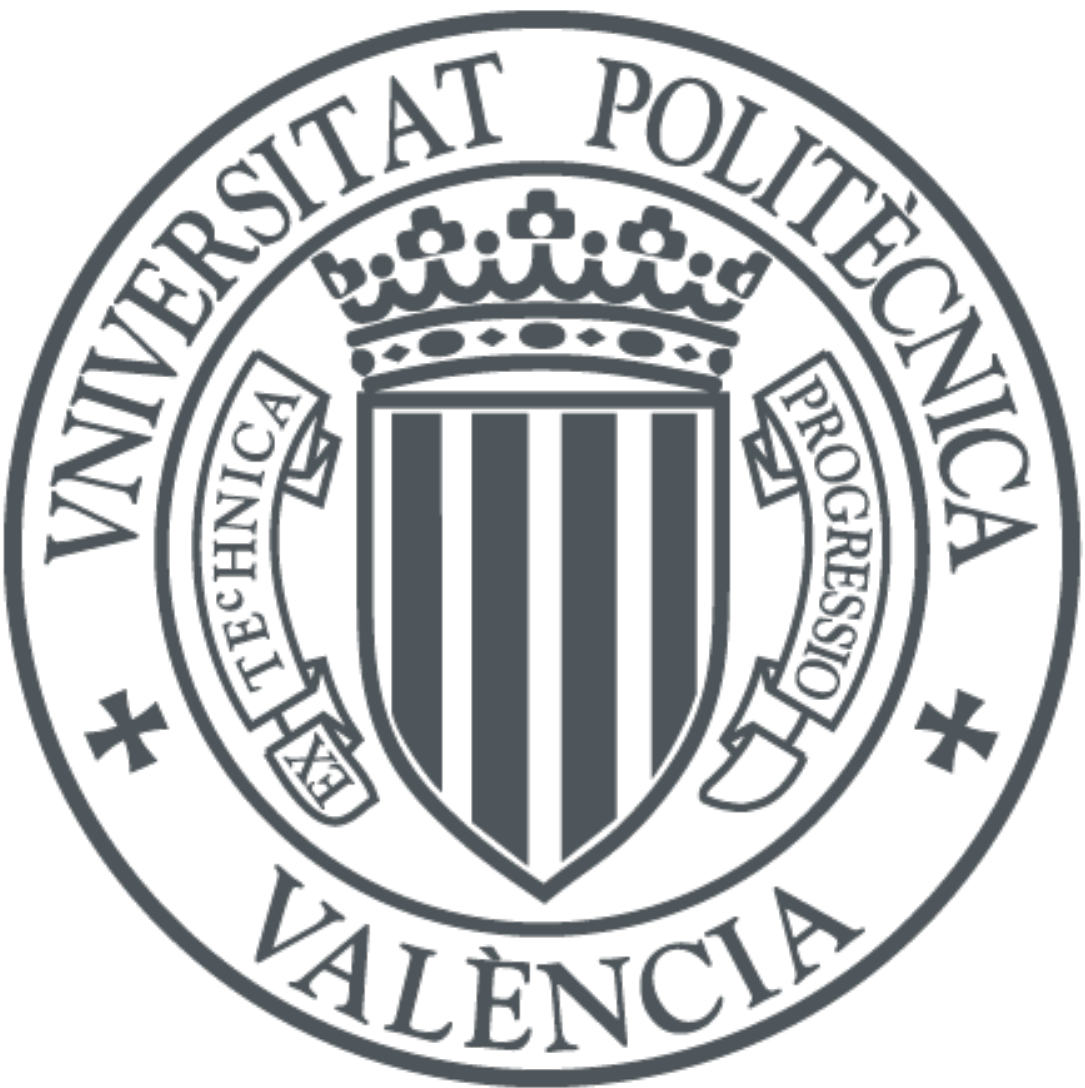

The final publication is available at

http://doi.org/10.1021/ja301082n

Copyright AMER CHEMICAL SOC

Additional Information 


\title{
Synthesis design and structure of a new multipore zeolite with interconnected 12- and 10-MR channels
}

\author{
Manuel Moliner ${ }^{1}$, Tom Willhammar ${ }^{2}$, Jorge González ${ }^{1,3}$, Fernando Rey ${ }^{1}$, Jose L. Jorda ${ }^{1}$, \\ Xiaodong $\mathrm{Zou}^{2^{*}}$, Avelino Corma ${ }^{1^{*}}$ \\ ${ }^{1}$ Instituto de Tecnología Química (UPV-CSIC), Universidad Politécnica de Valencia, Consejo Superior de \\ Investigaciones Científicas, Valencia, 46022, Spain \\ ${ }^{2}$ Berzelii Centre EXSELENT on Porous Materials and Inorganic and Structural Chemistry, Department of \\ Materials and Environmental Chemistry, Stockholm University, SE-106 91 Stockholm, Sweden. \\ ${ }^{3}$ Escuela de Ciencias Químicas, Universidad de Colima, Colima, 28040, Mexico. \\ *Corresponding author: E-mail address: acorma@itq.upv.es
}

\section{1.- Introduction}

Despite the large number of reported zeolites, ${ }^{[1]}$ the discovery of a new material with unique structural characteristics, such as pore shape, size and channel dimensionality, is always attractive because of potential new and/or improved applications. ${ }^{[2]}$ Zeolites are widely used as catalysts, and probably one of their most stunning features is their capability to induce different product selectivities depending on pore topology ${ }^{[3]}$ In this sense, the preparation of new zeolites with intersecting different sized channels allows the selective diffusion of reactants with different dimensions, with potential unique molecular traffic through the zeolite, and inducing more favorable orientations to react and give the desired product. ${ }^{[4]}$

Important advances have been achieved in the synthesis of structures with intersecting extralarge and large, ${ }^{[5]}$ extra-large and medium, ${ }^{[6]}$ and specially, large and medium ${ }^{[7]}$ pores. This last type of zeolites can also be of potential practical interest because they can combine in the same solid the pore topologies of medium and large pore zeolites.

Recently, we have reported the synthesis of a new complex structure, ITQ-39 zeolite, which is formed by an intergrowth of three different polymorphs, all of them containing threedimensional intersecting pair-wise 12 -membered rings (MR) and 10-MR pore systems. ${ }^{\left[{ }^{[8]}\right.}$ ITQ39 has been synthesized as silicoaluminate using as organic structure directing agent (OSDA) large dicationic piperidine derivatives (see OSDA2 and OSDA3 in Figure 1). Those OSDAs show a dramatic phase directing effect when their size and shape is tailored by introducing methyl, ethyl or propyl chains. ${ }^{[9]}$ Indeed, ITQ-39 can be synthesized in a broader Si/Al ratio when 
OSDA3 is used instead of OSDA2, avoiding in such case the crystallization of the competing ZSM-5 phase.

One of the polymorphs conforming ITQ-39, polymorph C (ITQ-39c), contains double four member-rings (D4R) in its structure, ${ }^{[8]}$ but is only present in $10 \%$ enrichment in the ITQ-39 intergrowth. It is well known the directing effect of Ge towards zeolites containing D4R in their structure. ${ }^{[10]}$ Indeed, the proposed theoretical structures for polymorph C of Beta zeolite family ${ }^{[11]}$ and polymorph C of CON family, ${ }^{[12]}$ both containing D4R in their frameworks, were first synthesized as pure phases when $\mathrm{Ge}$ was introduced, together with $\mathrm{Si}$, in the gel preparation (ITQ-17 and ITQ-24, respectively). ${ }^{[13]}$

Here, we will show a complete and rational experimental study with the main objective to direct the synthesis of ITQ-39c zeolite or other related zeolites containing large and medium pores having D4R in their structures. As it will be described, a new zeolite has achieved, ITQ38 , which is closely related to the polymorph C of ITQ-39. Both contain similar framework density (16.1 T atoms/1000 $\AA^{3}$ ), share a common plane along the [100] structure projection, and both are built from the same building unit. The discovery of ITQ-38 and its structural elucidation further confirms the excellent directing effect of dicationic piperidine molecules towards zeolites with interconnected large and medium pore zeolites when working in the adequate synthesis conditions.

\section{2.- Experimental}

\section{1.- OSDAs synthesis}

The syntheses of OSDA2 and OSDA3 have been previously described. ${ }^{[9]}$ OSDA1 was prepared as follows: $10 \mathrm{~g}$ of pyrrolidine (Sigma-Aldrich, 99\%) was dissolved in $100 \mathrm{ml}$ of ethanol (SigmaAldrich, $>99 \%$ ). The solution was acidified with $\mathrm{HCl}$ (Fluka, $5 \mathrm{~N}$ in methanol) until $\mathrm{pH}=7.5$, cooling down the mixture continuously at $273 \mathrm{~K}$. Then, $10 \mathrm{~g}$ of 1-methyl-4-piperidone (SigmaAldrich, $99 \%$ ) was added, followed by $3.5 \mathrm{~g}$ of sodium cyanoborohydride $\left(\mathrm{NaBH}_{3} \mathrm{CN}\right.$, Fluka, >95 $\%)$. The resultant mixture was stirred during 72 hours at room temperature.

Next, $\mathrm{HCl}$ is added slowly until $\mathrm{pH}$ close to 2 , being the $\mathrm{HCN}$ removed by nitrogen flow. The resulting solution was concentrated and then, a $\mathrm{KOH}$ solution was added until $\mathrm{pH}>12$. The mixture was satured with $\mathrm{NaCl}$. Finally, the diamine 1-methyl-4-pyrrolidin-1-yl-piperidine (MPP) was extracted with diethyl ether and dried with anhydrous $\mathrm{MgSO}_{4}$. 
$10.4 \mathrm{~g}$ of MPP was dissolved in $80 \mathrm{ml}$ of $\mathrm{MeOH}$, and then, $42 \mathrm{~g}$ of methyl iodide was added. After 7 days under stirring at room temperature, a white precipitated was achieved, being filtered and washed with methanol and diethyl ether. Finally, the solid was dried under high vacuum. The iodide salt was converted to the hydroxide salt by treatment with a hydroxide anion exchange resin.

\section{2.- Zeolite synthesis}

In a typical zeolite synthesis procedure, boric acid (99.5\%, Aldrich) or alumina (74.6\%, Condea) and germanium oxide (99\%, Aldrich) were dissolved in the OSDA hydroxide solution. Colloidal silica (Ludox AS-40, Aldrich) was added, followed by $\mathrm{NH}_{4} \mathrm{~F}$ (98\%, Aldrich) if necessary. The gels were allowed to reach the desired water ratio by evaporation, and then, transferred to a Teflon lined stainless autoclaves and heated at $175 \mathrm{o}^{\mathrm{C}}$ during 14 days. The solids were recovered by filtration, extensively washed with distilled water, and dried at $90^{\circ} \mathrm{C}$ overnight.

\section{3.- Characterization}

X-ray powder diffraction (XRPD) data were collected using a Panalytical X'Pert PRO diffractometer with Bragg-Brentano geometry, using CuK $\alpha$ radiation $\left(\lambda_{1}=1.5406 \AA, \lambda_{2}=1.5441 \AA\right.$, $\mathrm{I}_{2} / \mathrm{I}_{1}=0.5$; divergence slit: fixed $=1 / 160$; goniometer arm length: $240 \mathrm{~mm}$; detector: Panalytical $X^{\prime}$ Celerator; tube voltage and intensity: $45 \mathrm{kV}, 40 \mathrm{~mA}$; scan range: $3.0 \circ$ to $75.0 \circ(2 \theta)$, scan step size: 0.017 (29); counting time: $2400 \mathrm{~s} / \mathrm{step})$. Prior to the measurement of the calcined material, the sample was calcined in situ at $823 \mathrm{~K}$ for 5 hours under a continuous flow of dry air in an Anton Parr XRK-900 reaction chamber attached to the diffractometer, and allowed to cool again at room temperature.

High-resolution powder diffraction data for crystalline ITQ-38 were collected at Beamline BM01B at ESRF $(\lambda=0.5198 \AA ̊ A)$, using a calcined sample placed in a sealed glass capillary.

The chemical analysis was performed in a Varian 715-ES ICP-OES instrument, after dissolution of the solid in a $\mathrm{HNO}_{3} / \mathrm{HCl} / \mathrm{HF}$ aqueous solution. The organic content of the as-made materials was determined by elemental analysis performed on a SCHN FISONS elemental analyzer.

The morphology of the samples was studied by scanning electron microscopy (SEM) using a JEOL JSM-6300 microscope.

Textural properties were determined by $\mathrm{Ar}$ and $\mathrm{N}_{2}$ adsorption-desorption isotherms measured at 87 and $77 \mathrm{~K}$, respectively with a Micromeritics ASAP 2020. 


\section{3.- Results}

\section{1.- Synthesis}

As it has been described above, germanium shows a remarkable directing effect towards zeolites containing D4R units. ${ }^{[10]}$ This fact is explained because Ge-O-Si angle is smaller than SiO-Si, stabilizing the D4R cages when Ge atoms are present. ${ }^{[14]}$ Also, a similar directing effect has been also observed when syntheses are carried out in presence of fluoride anions. ${ }^{[15]}$ In this case, it has been observed that fluoride ions are preferentially located inside of D4R units, stabilizing those small cages by the formation of five-coordinated $\mathrm{SiO}_{4 / 2} \mathrm{~F}^{-}$units. ${ }^{[16]}$ Following those two premises, we designed two sets of exploratory experimental designs for synthesis of new porous materials in presence of Ge and fluoride anions (see Table 1). Synthesis variables such as germanium, boron, aluminium, and gel concentration, were investigated using dicationic piperidine derivatives OSDA1 and OSDA2 (see Figure 1). A total of 30 experiments were performed, achieving the two phase diagrams summarized in Figure $2 \mathrm{~A}$ and $2 \mathrm{~B}$. As it can be seen, BEC zeolite is formed in presence of high Ge contents in the synthesis gel for both OSDAs. This is not surprising, since BEC has been often described as one of the most stable structures in Ge-rich gels with a large variety of OSDAs. ${ }^{[13 a]}$ However, the phase selectivity is very different depending on the size and flexibility of the used OSDA when working at higher $\mathrm{Si} / \mathrm{Ge}$ ratios. The medium-sized OSDA1 directs to the formation of the chlatrate octadecasil (AST), which structure is also rich in D4Rs, while the large-sized and flexible OSDA2 directs towards the formation of ZSM-5 (MFI) structure. This outcome has been rationalized by the similar flexibility of OSDA2 and TPA, which is the preferred OSDA for MFI synthesis. ${ }^{[9]}$

From those previous findings, we can conclude that three very stable phases (BEC, AST, and $\mathrm{MFI}$ ) are formed in most of the explored areas, when syntheses are carried out in fluoride media. However, the fact that AST chlatrate is obtained in a wide range of reaction conditions when OSDA1 is used as template, reveals the higher directing effect of Ge and $F$ than the organic molecule, since $3 / 4$ of the total T-sites in AST chlatrate are located at D4R units. Taking all the above into account it appears that a different strategy must be applied in order to obtain open structures and, most importantly, to change significantly the phase selectivity towards structures other than the very stable BEC, AST and MFI.

Recently, the remarkable impact of the mobilizing agent (hydroxide or fluoride anions) in zeolite synthesis on phase selectivity has been reviewed by Zones et al. ${ }^{[17]}$ They describe that 
materials with open structures (low framework densities) can be achieved in alkaline media in presence of large aluminium or boron content under diluted conditions. ${ }^{[18]}$ Then, following that premise, we decided to move towards alkaline media in order to study the phase selectivity of OSDA1 and OSDA2. The experimental design for the study in alkaline media is described in Table 2, where a total of 48 new experiments for both OSDAs are summarized. As seen in Figure 3, different phases are achieved in alkaline media that in fluoride media. OSDA2 directs the formation of Beta or MFI depending on the gel dilution, while OSDA1 directs the crystallization of BEC, AST, and mixtures of them in several synthesis conditions. However, in diluted concentrations $\left(\mathrm{H}_{2} \mathrm{O} / \mathrm{T}^{\mathrm{IV}}=10\right)$, a different unknown phase is also obtained as a mixture of phases together with BEC and AST. This new material is named ITQ-38.

ITQ-38 appears preferably at the highest gel dilution and using a Si/Ge ratio of 5 . Consequently, a new set of conditions was defined for optimizing the preparation of ITQ-38, and involve two $\mathrm{H}_{2} \mathrm{O} / \mathrm{T}^{\mathrm{IV}}$ ratios, three $\mathrm{Si} / \mathrm{Ge}$ values, and different aluminium and boron contents, yielding an experimental design with 24 experiments (see Table 3). As seen in Figure 4, pure ITQ-38 was achieved in presence of boron, Si/Ge ratios of 5 and 10, and high dilution conditions $\left(\mathrm{H}_{2} \mathrm{O} / \mathrm{T}^{\mathrm{TV}}=20\right)$. However the samples are not fully crystalline, but also contain an amorphous phase. Taking into account that the sample with $\mathrm{Si} / \mathrm{Ge}$ ratio of 5 shows less amorphous content than sample with $\mathrm{Si} / \mathrm{Ge}$ ratio 10 , a new synthesis was undertaken in where the $\mathrm{Si} / \mathrm{Ge}$ ratio was decreased while keeping the dilution constant in order to reach the crystalline ITQ-38. The selected conditions were: $\mathrm{Si} / \mathrm{Ge}=3, \mathrm{H}_{2} \mathrm{O} / \mathrm{T}^{\mathrm{IV}}=20, \mathrm{~B} / \mathrm{T}^{\mathrm{IV}}, \mathrm{OSDA} 1 / \mathrm{T}^{\mathrm{IV}}=$ 0.25 , at $175^{\circ} \mathrm{C}$. After 14 days, a fully crystalline ITQ-38 zeolite was achieved.

\section{2.- Characterization and structure solution}

X-ray powder diffractograms (XRPD) of the ITQ-38 sample as-prepared and after calcination at $550^{\circ} \mathrm{C}$ are shown in Figure 5, indicating that the structure remains stable after the removal of the organic moiety. Elemental analyses of the as-prepared ITQ-38 reveal that the organic cation 1,1-dimethyl-4-(1-methylpirrolidine-1-yl)piperidinium remains intact inside the ITQ-38 structure, showing a $\mathrm{C} / \mathrm{N}$ molar ratio of 6.1 , while thermogravimetric analyses give a weight loss of $15 \%$ wt (see Figure 6 ).

In order to know the textural properties of ITQ-38, $\mathrm{N}_{2}$ and Ar adsorption measurements were performed. The $\mathrm{N}_{2}$ adsorption isotherm at $77 \mathrm{~K}$ shown in Figure 7 reveals the microporous nature of this material. The BET (Brunauer-Emmett-Teller) surface area is $367 \mathrm{~m}^{2} / \mathrm{g}$ with a micropore volume of $0.16 \mathrm{~cm}^{3} / \mathrm{g}$. High-resolution $\mathrm{Ar}$ adsorption isotherm at $87 \mathrm{~K}$ allows to obtain an accurate experimental pore distribution by applying the Howarth-Kamazoe 
formalism. As seen in Figure 8, a bimodal narrow pore distribution centered at 5.5 and $6.6 \AA$ is observed, indicating that the ITQ-38 may present a large and medium pore channel system in its structure. The relative high adsorption capacity also suggests that this zeolite may be formed by a tridirectional system of pores.

Additionally, scanning electron microscopy (SEM) images (see Figure 9) shows very small crystallites $(0.1-0.2 \mu \mathrm{m})$. This crystal size precludes the solution by X-ray single-crystal diffraction methods.

Then, the structural elucidation of the ITQ-38 zeolite has been attempted from high-resolution X-ray powder diffraction (HR-DRPX) data collected using synchrotron radiation (see XRD pattern in Figure 10). The XRD pattern was successfully indexed in a monoclinic unit cell $\left(a=13.02 \AA, b=12.70 \AA, c=21.25 \AA, \beta=96.870, V=3489 \AA^{3}\right)$ using the program TREOR ${ }^{[19]}$, and the study of the systematic extinctions suggests as possible space groups $P 2, P m$ or $P 2 / m$. However, the large peak overlapping even at very low $2 \theta$ angles due to the low symmetry of the material, the large complexity of the cell due to its framework density (experimental density = $15.9 \mathrm{~T} / 1000 \AA^{3}$ ) and relative large size, and, as observed later, the presence of stacking faults in the framework, precluded the structure resolution by X-ray powder diffraction (XRPD) direct methods. Consequently, transmission electron microscopy (TEM) methods were applied to solve the framework topology of ITQ-38.

ITQ-38 zeolite has been extensively studied by TEM. As seen in Figure 11, ITQ-38 contains prefect single crystals that give sharp diffraction spots (Figure 11-left), as well as small areas with intergrown crystals that give streaks in ED pattern (Figure 11-right). The presence of those nano-sized intergrowth domains makes the structure resolution of ITQ-38 not achievable using only X-ray powder diffraction data. However, crystallographic structure factor phases, required for structure solution, can be directly obtained from high resolution transmission electron microscopy (HRTEM) images. ${ }^{[20]}$ Following this methodology, very complex structures have been resolved in the last years. ${ }^{[21]}$

In this case, a new unit cell ( $a=23.59 \AA, b=12.85 \AA, c=21.22 \AA$ and $\beta=147.16 \circ)$ related to the previous one determined from XRPD has been obtained. The determination of the complete ITQ-38 framework structure has been accomplished using those unit cell parameters. The structure model has been refined geometrically with a distance least squares refinement, obtaining a RDLS value of 0.0027 . This structure model has $16.05 \mathrm{~T}$ atoms $/ 1000 \AA^{3}$, well in correspondence with experimental data $\left(15.9 \mathrm{~T} / 1000 \AA^{3}\right)$. HRTEM image along the [101] projection, further confirms the structure (see Figure 12). 
Along the [010] projection, the potential map shown in Figure 13 clearly illustrates the presence of alternating 12 - and $10-\mathrm{MR}$ pores in the same projection. This is very similar to ITQ22 (IWW). The layers containing the 12-MR are however connected in a different way forming alternating 6- and 10-MR instead of 8-MR. A structure model for ITQ-38 could be created with IWW as a starting point. The structure has a 3D pore system limited by $10-$ and 12-MR (see Figure 14). The model is built with all $\mathrm{T}$ atoms tetrahedrally coordinated to the framework in the monoclinic space group $P 2 / \mathrm{m}$.

As indicated by the streaks in the SAED pattern along the [010] direction (Figure 11 right), ITQ38 exhibits a small stacking disorder. The stacking disorder arises because layers propagating along the (010) and (101) direction of ITQ-38 (marked in red in the Figure 15) have two possibilities to connect to each other. In ITQ-38, the red layer and the yellow layers are related by a two-fold rotation around the [010] axis, and further connected to each other (see Figure 15). Lattice filtered HRTEM image recorded along the [010] direction shows that the connectivity of ITQ-38 is enriched in the new connectivity with alternating 10- and 6-MR, but the IWW-type of connectivity with $8 \mathrm{MR}$ is also present (see Figure 16).

Thus, for simplicity and comparison with IWW, a new change in the unit cell axis has been introduced, leading to a cell with $a=12.87 \AA, b=12.84 \AA, c=21.22 \AA$ and $\beta=96.23$ 으, $V=3486 \AA^{3}$ in good agreement with those previously obtained from XRPD data, and related to that described for IWW ( $\left.a=42.13 \AA, b=12.99 \AA, c=12.68 \AA, V=6940 \AA^{3}\right)$ but with only one half of the volume.

To confirm that the determined structure was representative of the whole sample, the unit cell parameters and symmetry of zeolite ITQ-38 were confirmed by a LeBail refinement of the experimental X-ray powder diffraction (XRPD) pattern collected using the laboratory diffractometer. The final refined cell parameters obtained using the program FullProf ${ }^{[22]}$ were $a=12.921 \AA, b=12.939 \AA, c=21.348 \AA, \beta=96.80^{\circ}$ and $V=3544.0 \AA^{3}$. However, the presence of stacking faults, even in low proportion (around $15 \%$ is observed by HRTEM in the measured crystals), combined with the large complexity of the cell precluded a satisfactory Rietveld refinement of the full structure. In this sense, attempts to minimize the differences between the observed and calculated XRPD produces an artificial and severe displacement of the oxygen atoms out of the physically reasonable positions. Therefore, we proceeded to simulate the theoretical XRPD pattern of the proposed structure of ITQ-38 for visual comparison with the experimental data, using the program FullProf. The background and profile parameters extracted from the previous LeBail refinement of the experimental data were used for this simulation. Taking into account the similarity between the layers of the intergrowth members 
(IWW and ITQ-38), we used the experimental values obtained for a sample of IWW with similar $\mathrm{Si} / \mathrm{Ge}$ ratio $(\mathrm{Si} / \mathrm{Ge}=4)$ to obtain an estimation of the Ge distribution in the different $\mathrm{T}$ sites of ITQ-38 structure. Both experimental and simulated XRPD patterns are shown in Figure 17, where it can be observed the good agreement between both, confirming that the proposed ITQ-38 structure is the main component of the material. The cell parameters and atomic coordinates are shown in Table 4.

\section{3.- Comparison between ITQ-38 and ITQ-39c}

The structures ITQ-38 and ITQ-39c are closely related, though different. Both of them have 16 unique $T$ atoms in the unit cell and crystallize in space group $P 2 / \mathrm{m}$. ITQ-39c contains one $T$ atom with 0.5 occupancy whereas ITQ-38 has all atoms with 1 occupancy. Viewed along the [100] the two structures show a very similar projected structure (see Figure 18). They both contain layers of 10-MR separated by layers of 6 - and 4-MR (in the sequence $6,6,4,6,6,4$ ). In contrast, when both materials are viewed along the [010] direction, they look different. ITQ-38 contains alternating 10- and 12-MR channels, whereas ITQ-39 has twin 12-MR channels (see Figure 19). It is possible to see the similarities within the building layer. The two structures are built form the same building unit but the connection between the consecutive units within the layer are made by different units in the two structures. The common building unit is shown in green in Figure 20-C. This common building unit has the same topology in the two structures but they are slightly distorted because of their further connectivity. The common units are connected to each other with the two (also similar units) shown in Figure 20-D. These two connecting units connect differently to the common building unit (see green connectors). Please also note that in ITQ-39c the four T atoms in the middle of the connecting unit fall very close to each other and have 0.5 occupancy.

\section{4.- Conclusions}

By rationalization of the synthesis procedure, it has been possible to direct the synthesis of a new zeolite, ITQ-38, containing large and medium pores in its structure. The structure has been elucidated by transmission electron microscopy, revealing the presence of very small intergrowth domains with IWW zeolite. This new material is highly related to the recently described polymorph C of ITQ-39 (ITQ-39c), which is only present in 10\% enrichment in the ITQ-39 intergrowth zeolite. Those two zeolites, ITQ-38 and ITQ-39c, contain the same [100] projection and both are built from the same building unit. The optimization of the synthesis conditions of ITQ-38, together with rational studies of dicationic piperidine derivative molecules as OSDAs, is a current subject of interest on our group. 


\section{Acknowledgements}

Financial support by the Spanish MICINN (MAT2009-14528-CO2-01 and MAT2006-14274-CO201), Consolider Ingenio 2010-Multicat, Generalitat Valenciana by the PROMETEO program, UPV through PAID-06-11 (n.1952), the Swedish Research Council (VR), the Swedish Governmental Agency for Innovation Systems (VINNOVA) and Göran Gustafsson Foundtion is acknowledged. Manuel Moliner also acknowledge to "Subprograma Ramon y Cajal" for the contract RYC-2011-08972. The authors thank beamline BM01B at ESRF in Grenoble for beamtime allocation (Exp CH-2493). 
Figures:

Figure 1: Organic structure directing agents (OSDAs) used in zeolite synthesis

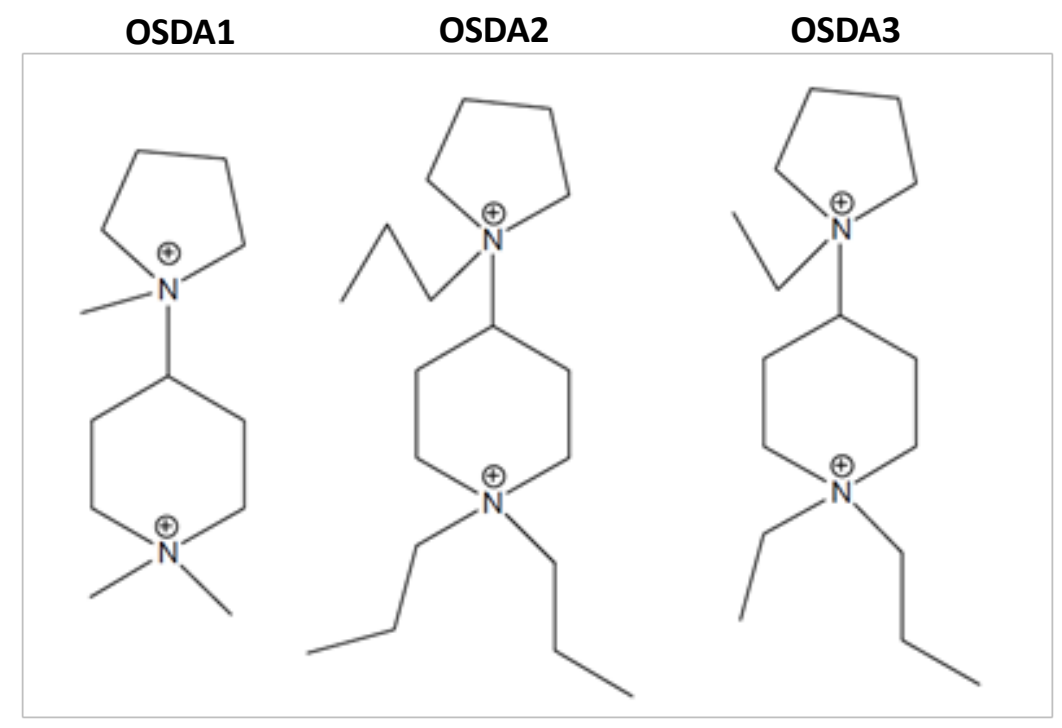


Figure 2: Phase diagrams obtained when OSDA1 (A) and OSDA2 (B) are used in fluoride media

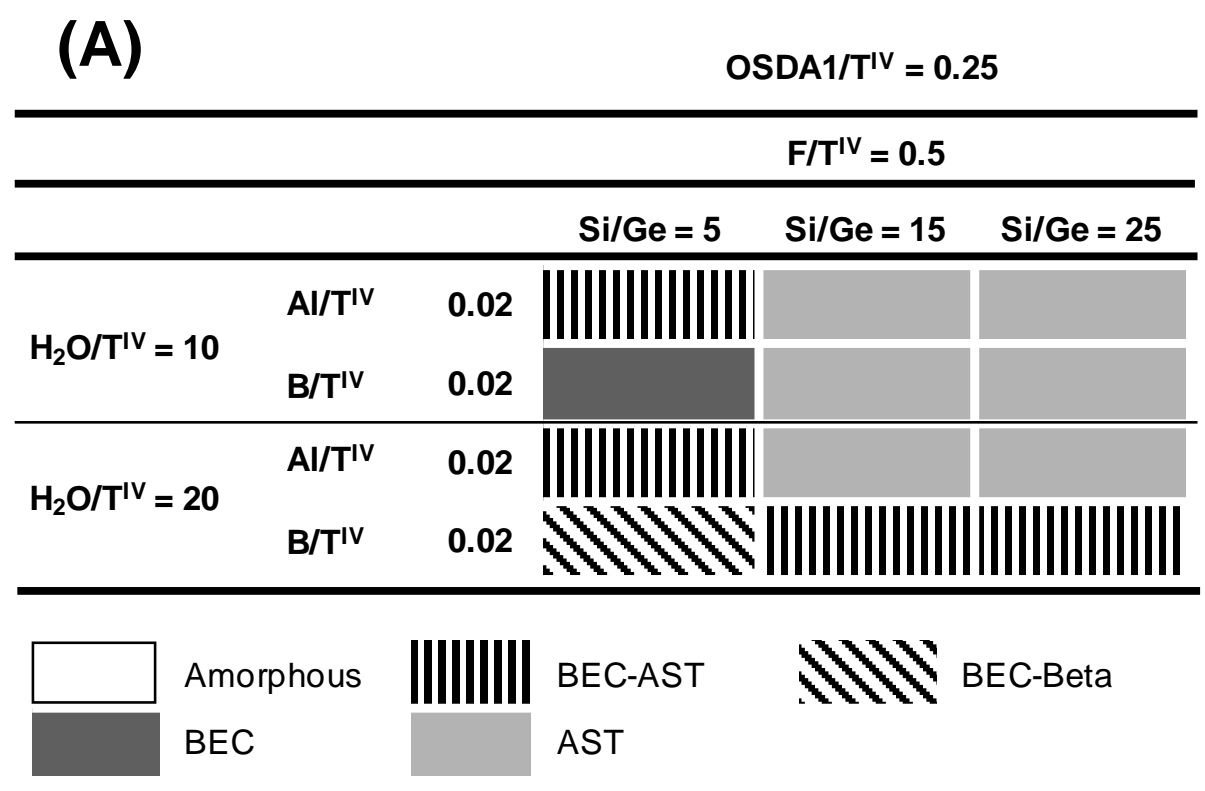

\begin{tabular}{|c|c|c|c|c|c|}
\hline (B) & & & \multicolumn{3}{|c|}{ OSDA2/T' ${ }^{I V}=0.25$} \\
\hline & & & \multicolumn{3}{|c|}{$\mathrm{F} / \mathrm{T}^{\mathrm{IV}}=0.5$} \\
\hline & & & $\mathrm{Si} / \mathrm{Ge}=\mathbf{2}$ & $\mathrm{Si} / \mathrm{Ge}=5$ & $\mathrm{Si} / \mathrm{Ge}=15$ \\
\hline \multirow{3}{*}{$\mathrm{H}_{2} \mathrm{O} / \mathrm{T}^{\mathrm{IV}}=3$} & $T^{I I I / T} T^{I V}$ & 0 & & & \\
\hline & $\mathrm{Al} / \mathrm{T}^{\mathrm{IV}}$ & 0.033 & & & \\
\hline & $\mathrm{B} / \mathrm{T}^{\mathrm{IV}}$ & 0.033 & & & \\
\hline \multirow{3}{*}{$\mathrm{H}_{2} \mathrm{O} / \mathrm{T}^{\mathrm{IV}}=10$} & 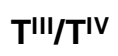 & 0 & & & \\
\hline & $\mathrm{Al} / \mathrm{T}^{\mathrm{IV}}$ & 0.033 & & & \\
\hline & $\mathrm{B} / \mathrm{T}^{\mathrm{TV}}$ & 0.033 & & & \\
\hline & \multicolumn{3}{|c|}{ Amorphous } & MFI-BEC & \\
\hline & & BEC & & MFI & \\
\hline
\end{tabular}


Figure 3: Phase diagrams obtained when OSDA1 and OSDA2 are used in alkaline media

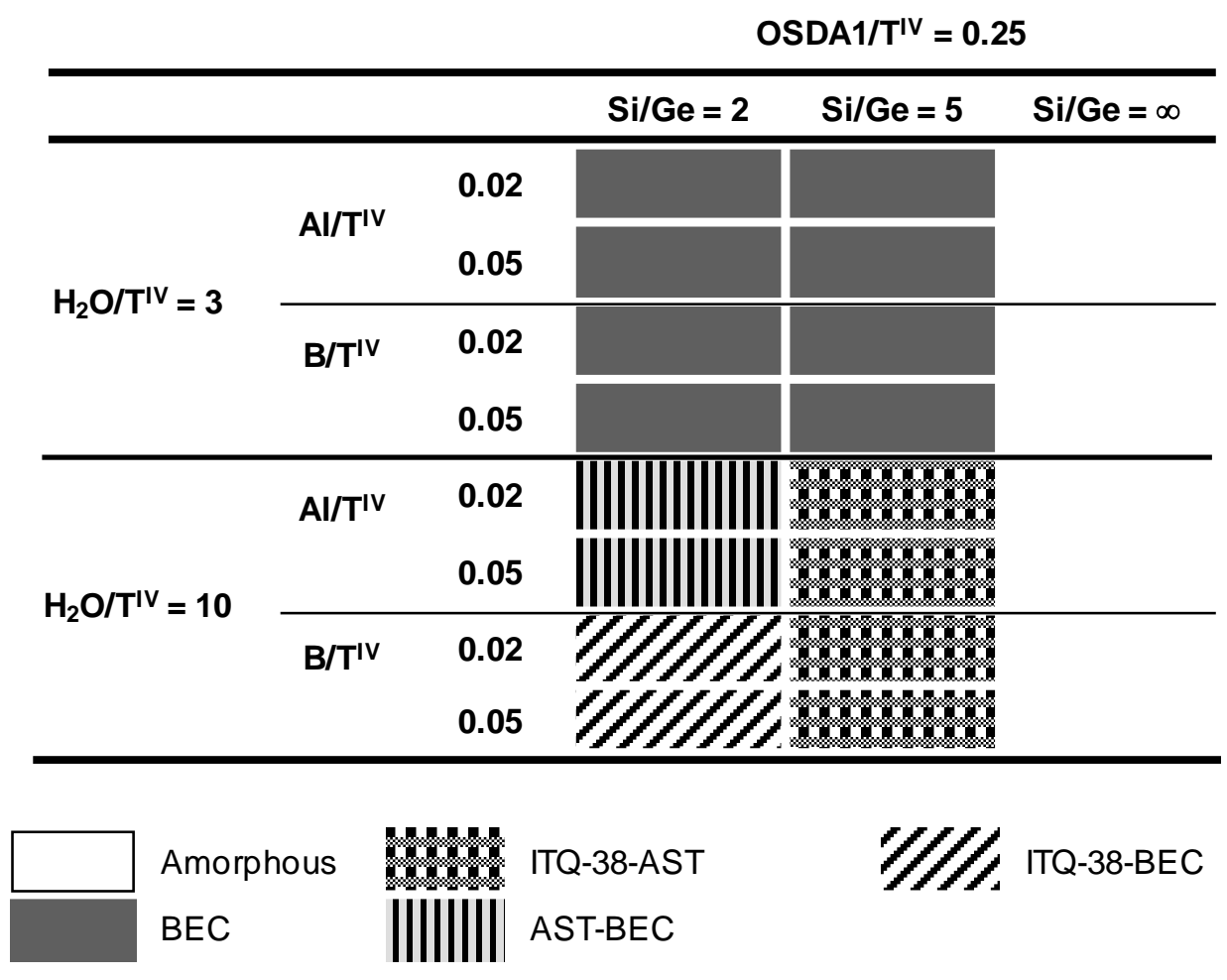

\begin{tabular}{|c|c|c|c|c|c|}
\hline & & & \multicolumn{3}{|c|}{ OSDA2/T' } \\
\hline & & & $\mathrm{Si} / \mathrm{Ge}=2$ & $\mathrm{Si} / \mathrm{Ge}=5$ & $\mathrm{Si} / \mathrm{Ge}=\infty$ \\
\hline \multirow{4}{*}{$\mathrm{H}_{2} \mathrm{O} / \mathrm{T}^{\mathrm{IV}}=3$} & $\mathrm{Al} / \mathrm{T}^{\mathrm{IV}}$ & 0.02 & & & \\
\hline & $\mathrm{Al} / \mathrm{T}^{\mathrm{IV}}$ & 0.05 & & & \\
\hline & $\mathrm{B} / \mathrm{T}^{\mathrm{IV}}$ & 0.02 & & & \\
\hline & $\mathrm{B} / \mathrm{T}^{\mathrm{IV}}$ & 0.05 & & & \\
\hline \multirow{4}{*}{$\mathrm{H}_{2} \mathrm{O} / \mathrm{T}^{\mathrm{IV}}=10$} & $\mathrm{Al} / \mathrm{T}^{\mathrm{IV}}$ & 0.02 & & & \\
\hline & $\mathrm{Al} / \mathrm{T}^{\mathrm{IV}}$ & 0.05 & & & \\
\hline & $\mathrm{B} / \mathrm{T}^{\mathrm{IV}}$ & 0.02 & & & \\
\hline & $\mathrm{B} / \mathrm{T}^{\mathrm{IV}}$ & 0.05 & & & \\
\hline & \multicolumn{2}{|c|}{ Amorphous } & & & MFI \\
\hline
\end{tabular}


Figure 4: Phase diagram achieved using OSDA1 in alkaline media during the ITQ-38 optimization

\begin{tabular}{|c|c|c|c|c|c|}
\hline & & & \multicolumn{3}{|c|}{ OSDA1/TIV = 0.25} \\
\hline & & & $\mathrm{Si} / \mathrm{Ge}=5$ & $\mathrm{Si} / \mathrm{Ge}=10$ & Si $/ G e=15$ \\
\hline \multirow{2}{*}{$\mathrm{H}_{2} \mathrm{O} / \mathrm{T}^{\mathrm{IV}}=10$} & $\mathrm{Al} / \mathrm{T}^{\mathrm{IV}}$ & $\begin{array}{l}0.02 \\
0.05\end{array}$ & 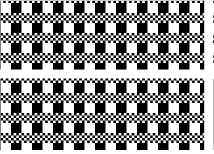 & (2) & \\
\hline & $\mathrm{B} / \mathrm{T}^{\mathrm{IV}}$ & $\begin{array}{l}0.02 \\
0.05\end{array}$ & 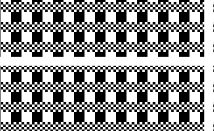 & 1 & - \\
\hline \multirow{4}{*}{$\mathrm{H}_{2} \mathrm{O} / \mathrm{T}^{\mathrm{IV}}=20$} & $\mathrm{Al} / \mathrm{T}^{\mathrm{IV}}$ & 0.02 & $\infty_{-\infty}^{\infty}$ & & \\
\hline & & 0.05 & $19 \times 1$. & & \\
\hline & $\mathrm{B} / \mathrm{T}^{\mathrm{IV}}$ & 0.02 & & & \\
\hline & & 0.05 & E= & & \\
\hline
\end{tabular}

\begin{tabular}{|c|c|}
\hline Amorphous & ITQ-38-AST \\
\hline ITQ-38 & AST \\
\hline
\end{tabular}


Figure 5: As-prepared and calcined XRD patterns of ITQ-38 zeolite

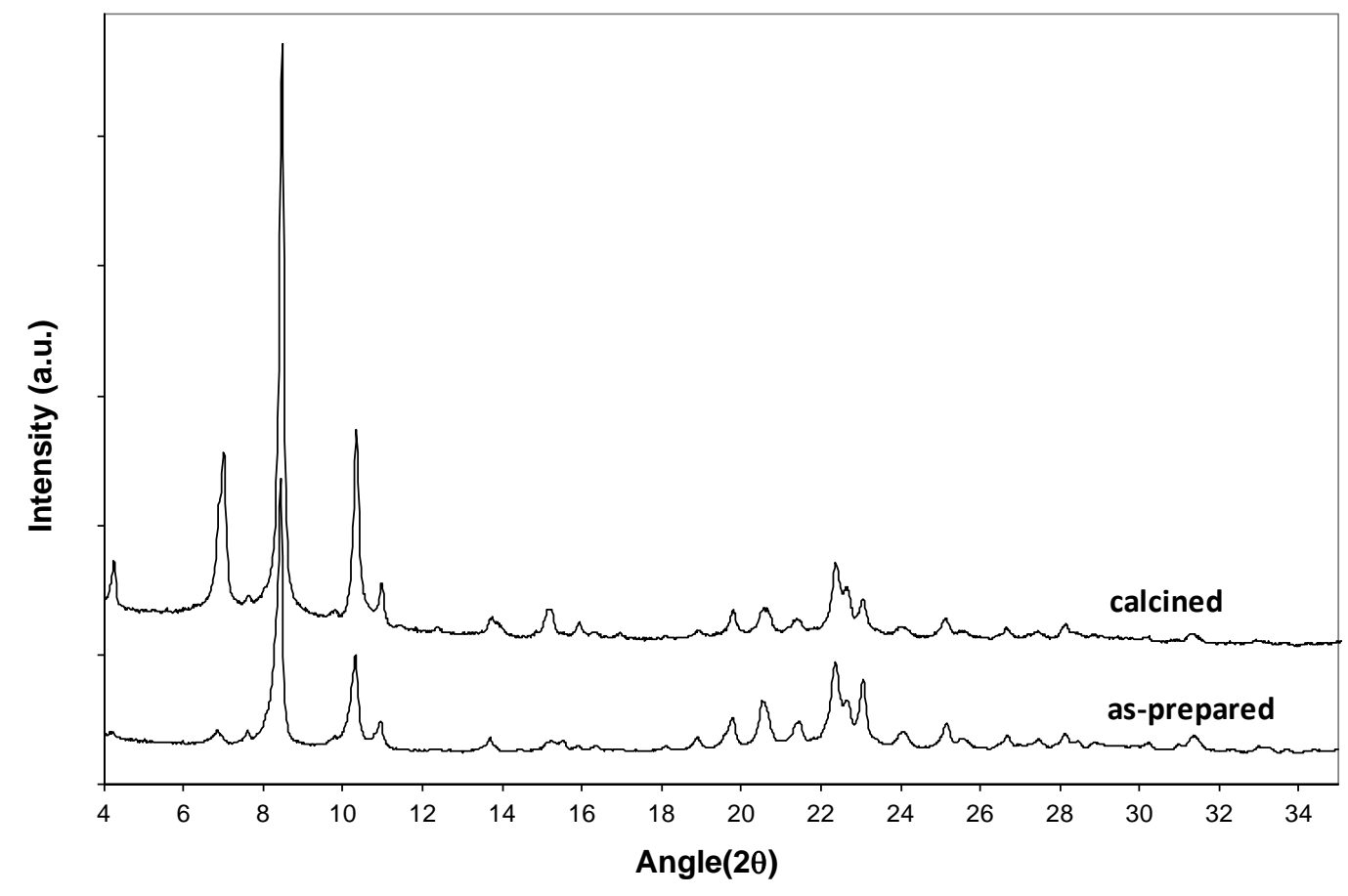


Figure 6: Thermogravimetric analysis of ITQ-38 zeolite

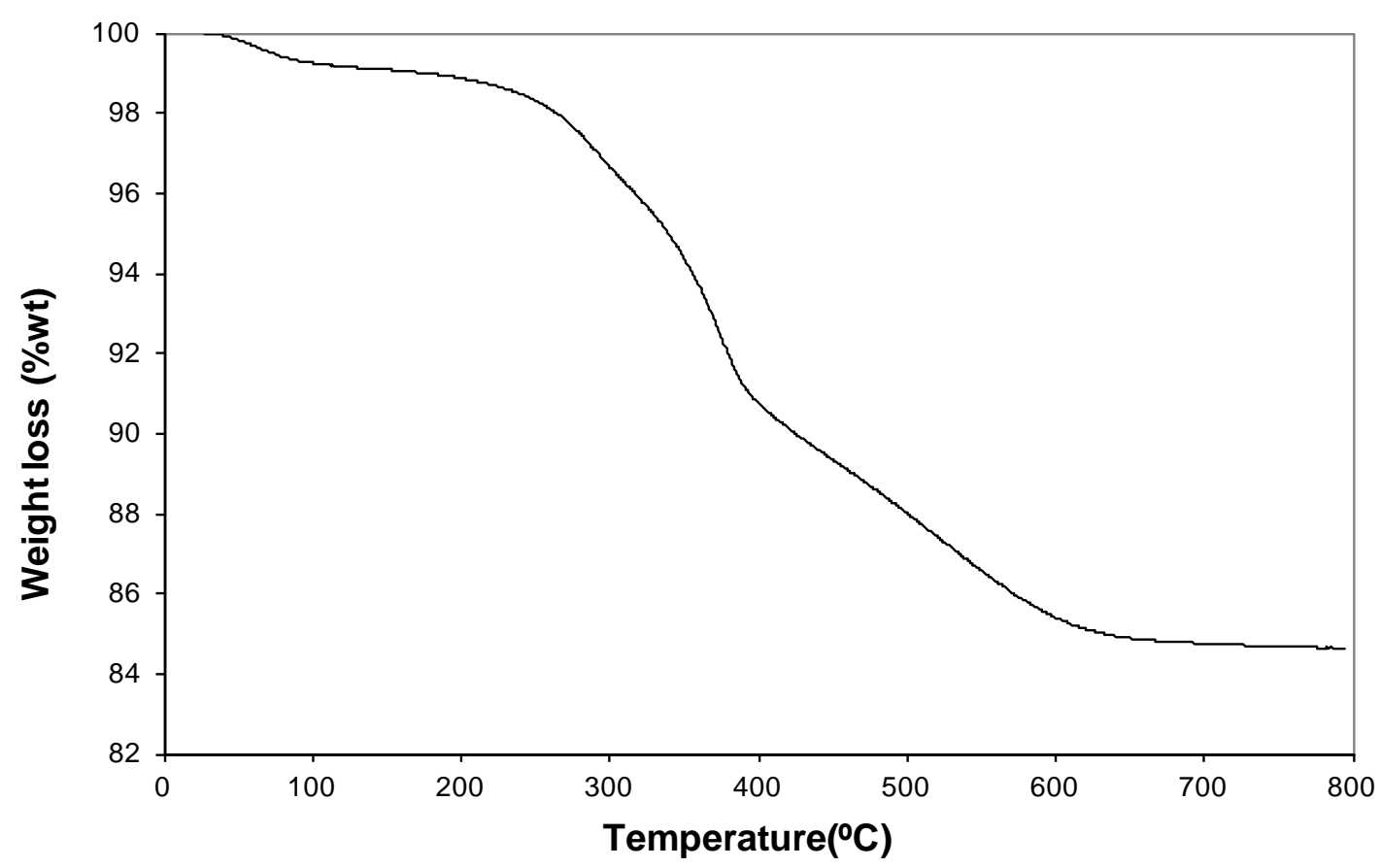


Figure 7: $\mathbf{N}_{2}$ adsorption isotherm of ITQ-38 zeolite

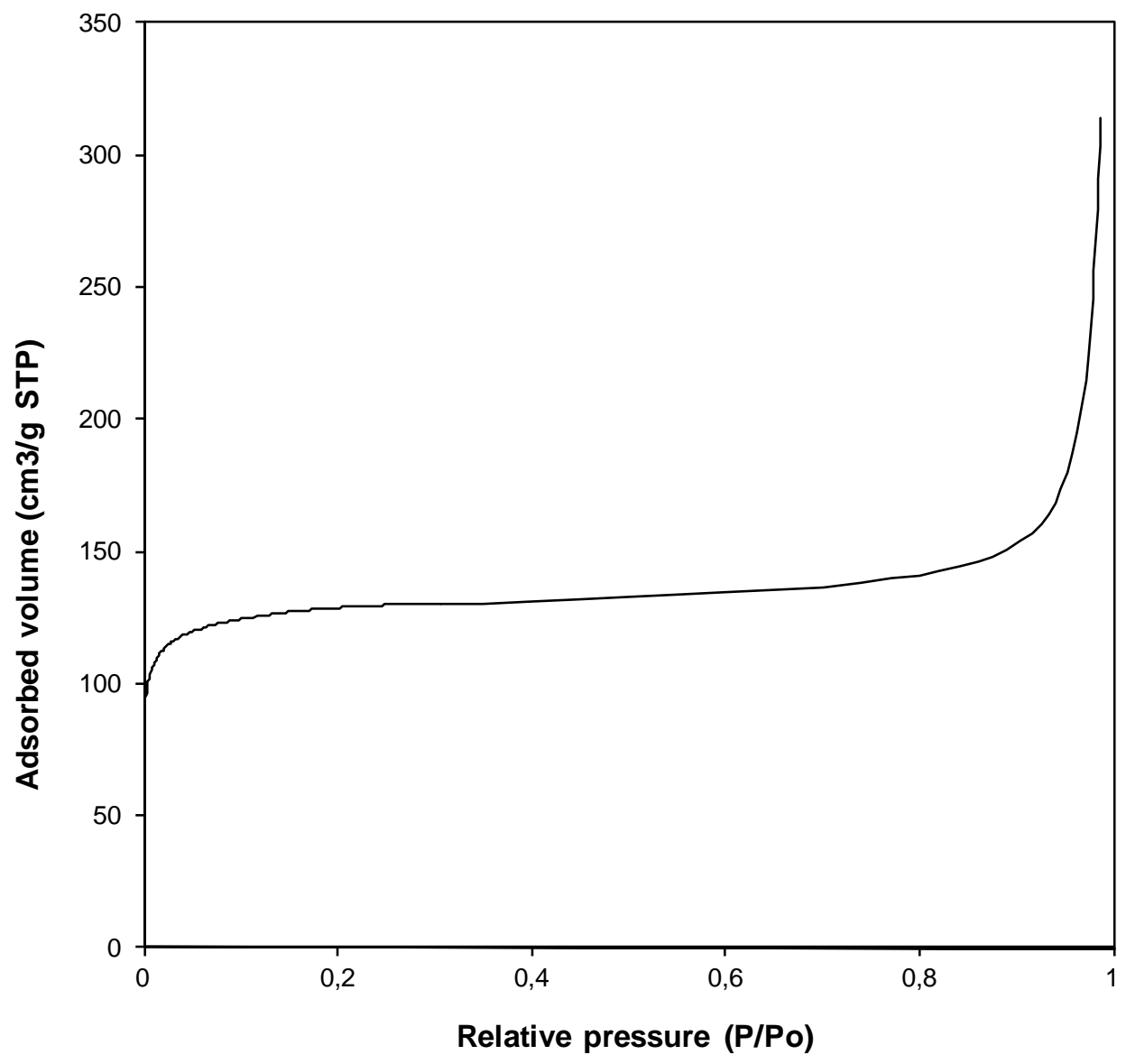


Figure 8: Experimental pore distribution of ITQ-38 zeolite measured from Ar adsorption

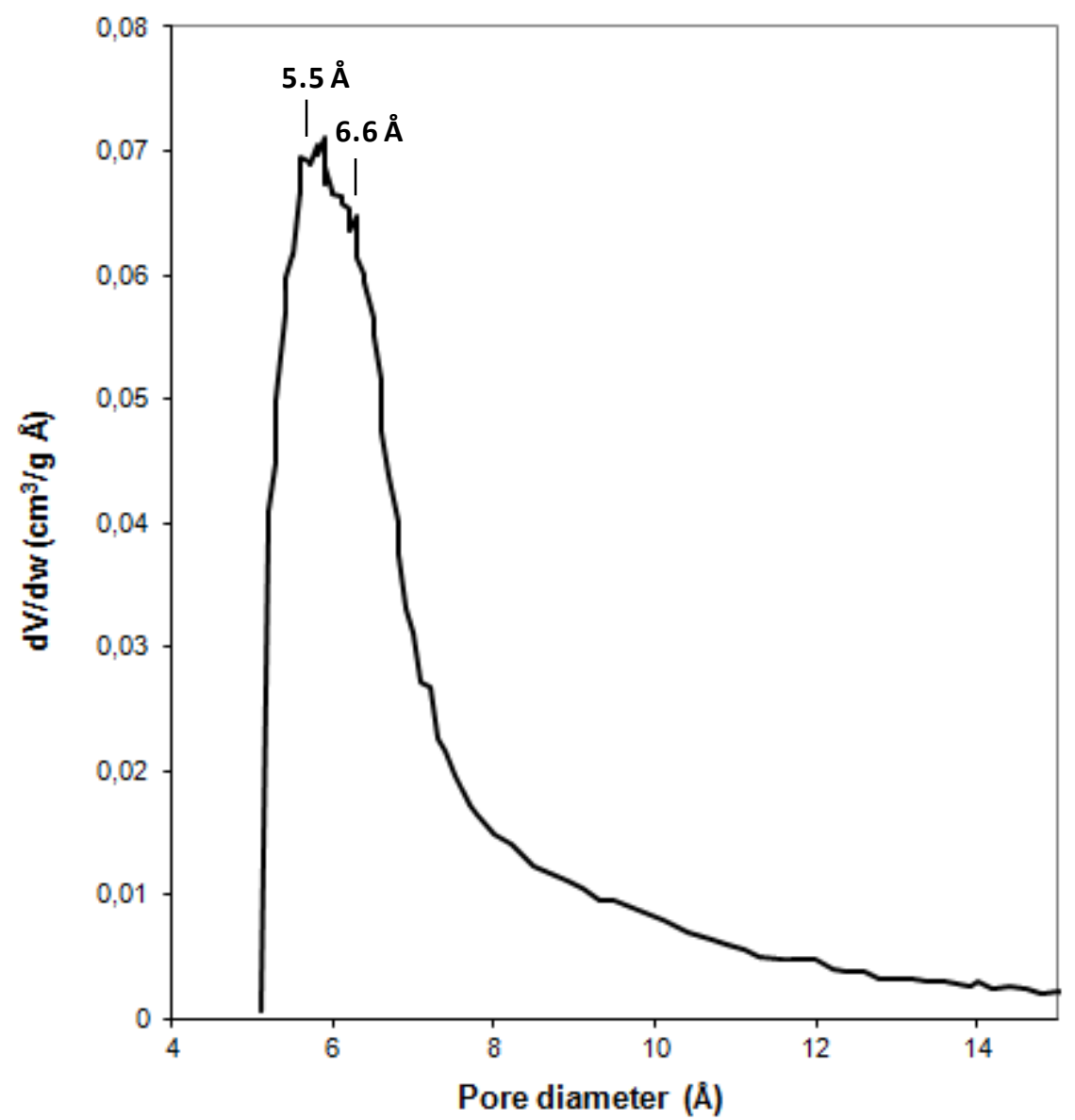


Figure 9: Scanning electron microscopy (SEM) image of ITQ-38 zeolite

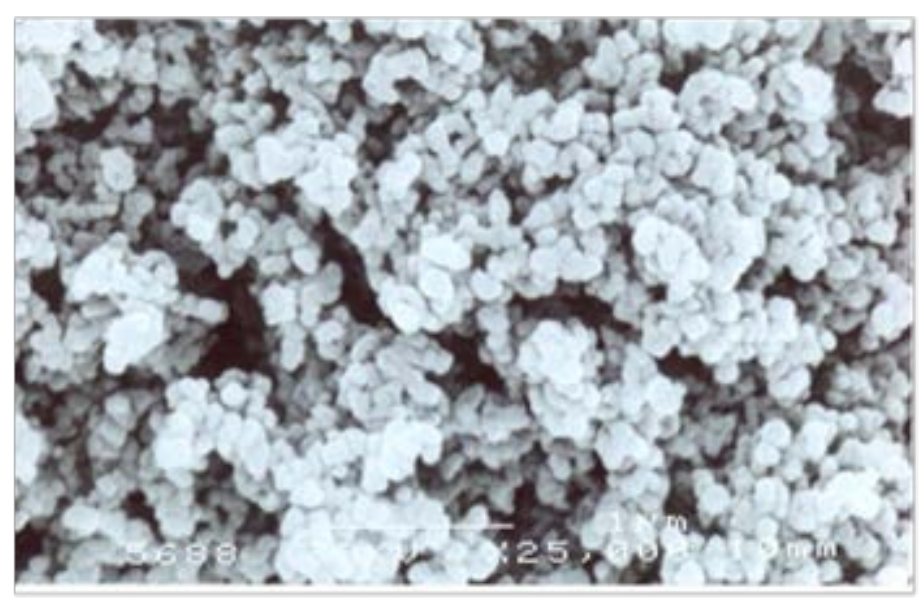


Figure 10: X-ray powder diffraction pattern of ITQ-38 collected using synchrotron radiation $(\lambda=0.5198 \AA)$

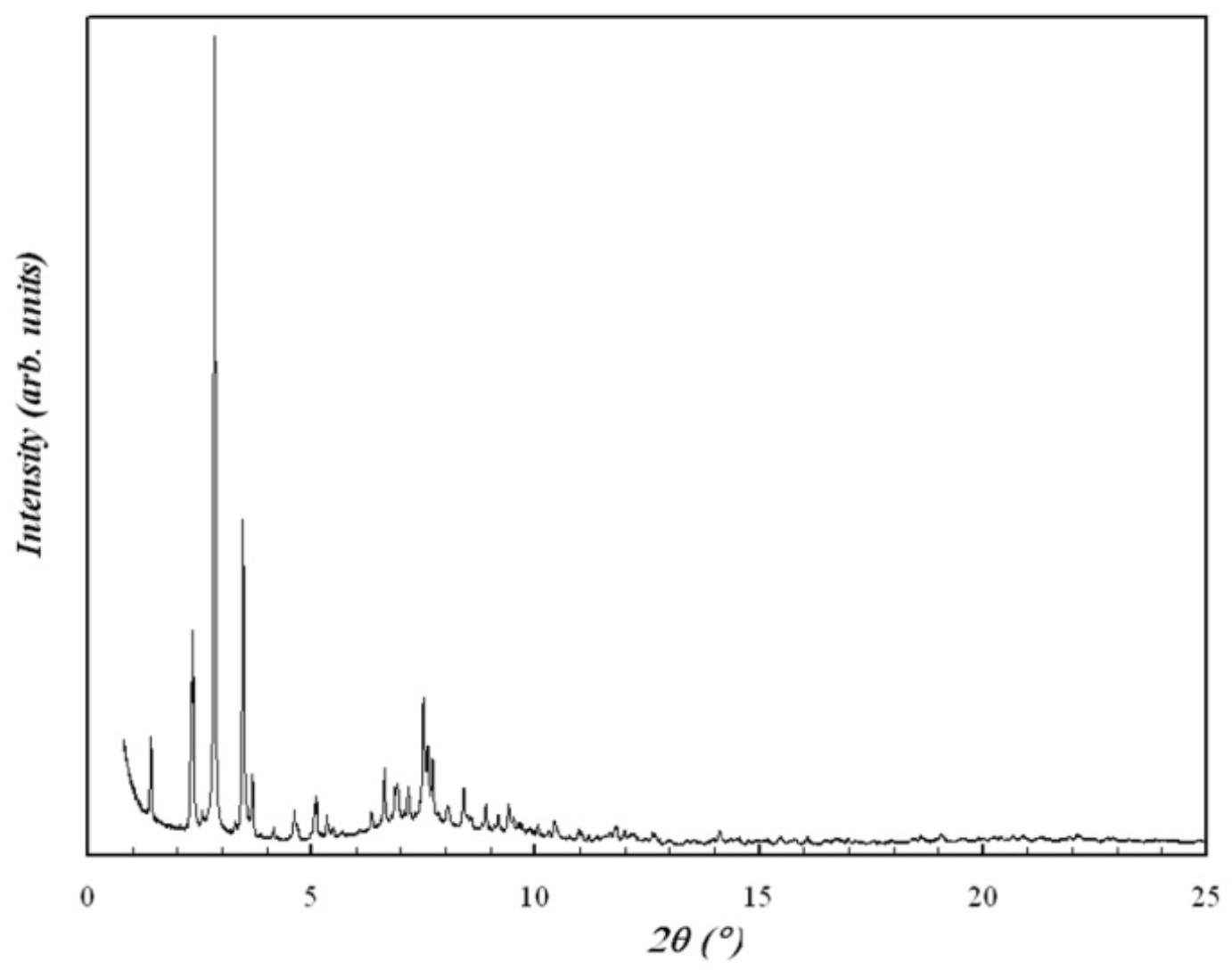


Figure 11: Diffraction patterns along the [010] direction from a single domain (left) and from an intergrown domain (right). The diffraction patterns are very dynamical.

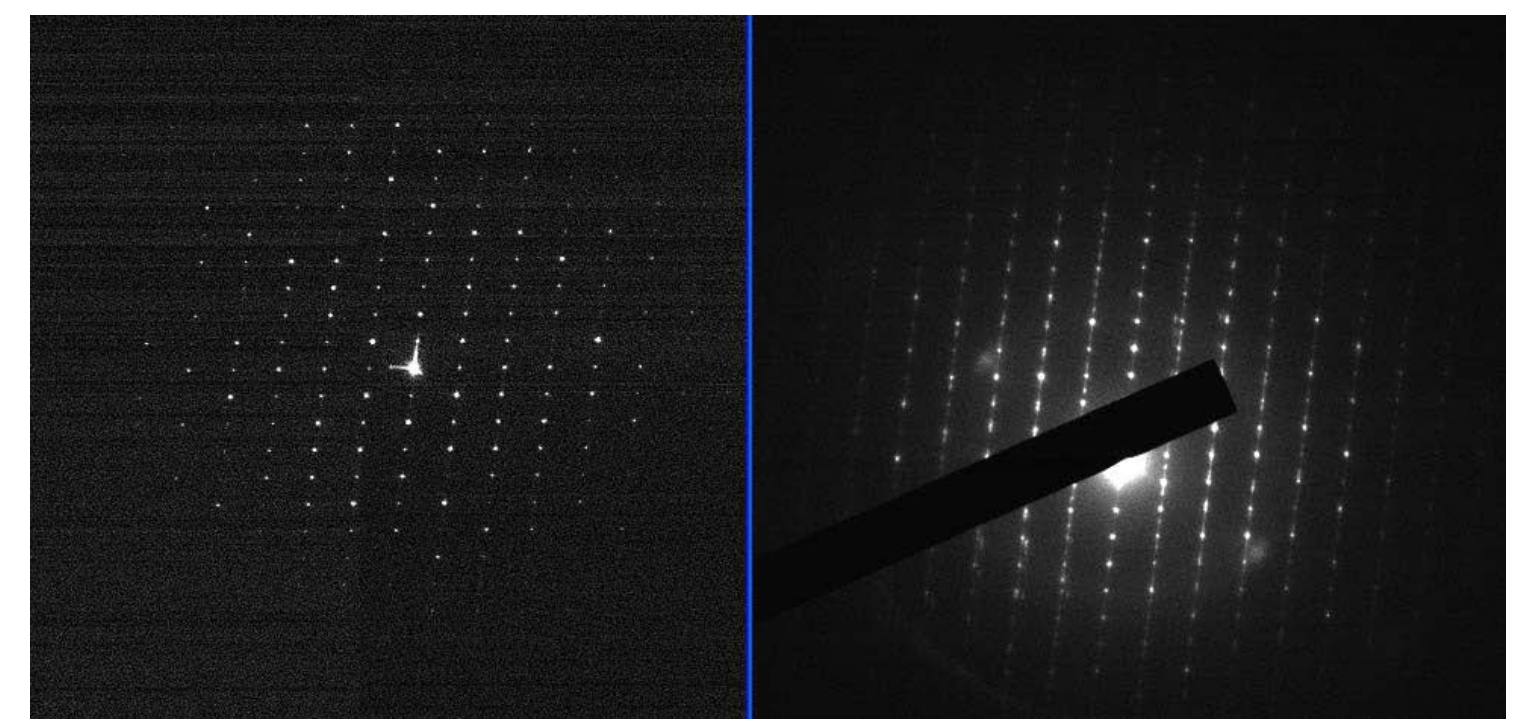


Figure 12: HRTEM image along the [101] confirms the structure. Lattice filtered image to the bottom left with a structure model overlaid.

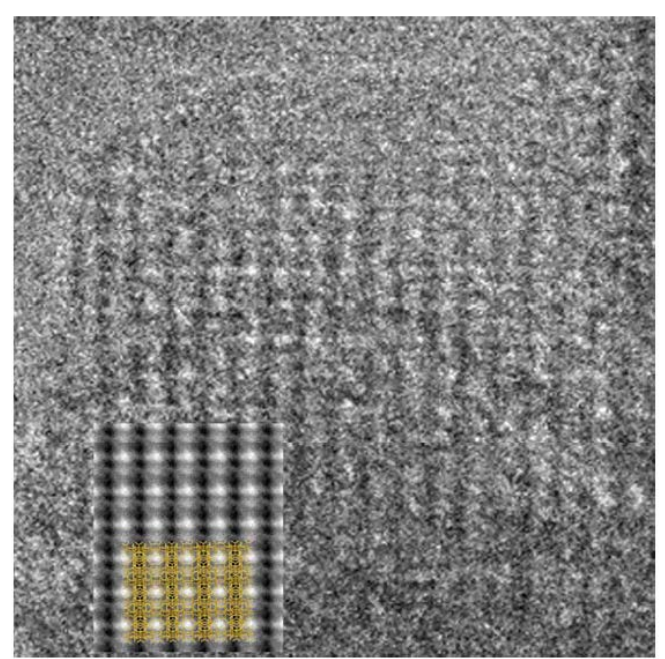


Figure 13: HRTEM image from an ordered domain along the [010] projection clearly shows 4, 5-, 6-,10- and 12 membered rings. The plane group is $p 2$ (phase residual $8^{\circ}$ ).

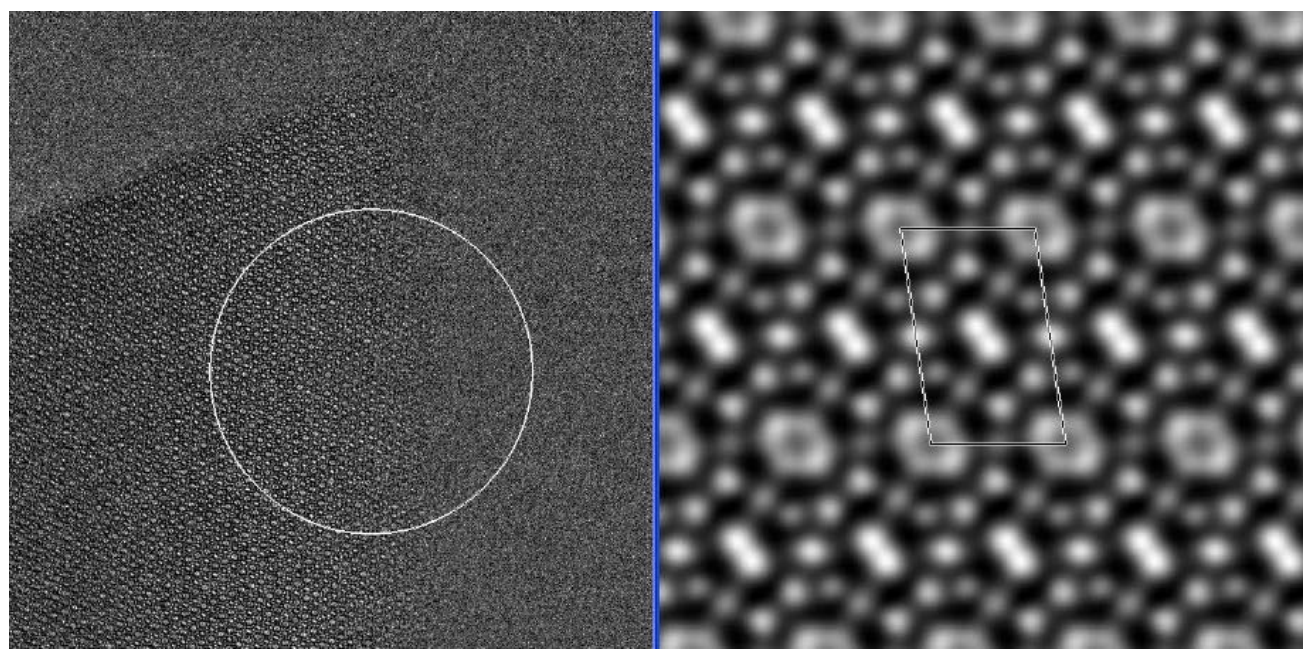


Figure 14: The structure model of ITQ-38 viewed along the [100] and [010] directions, respectively.
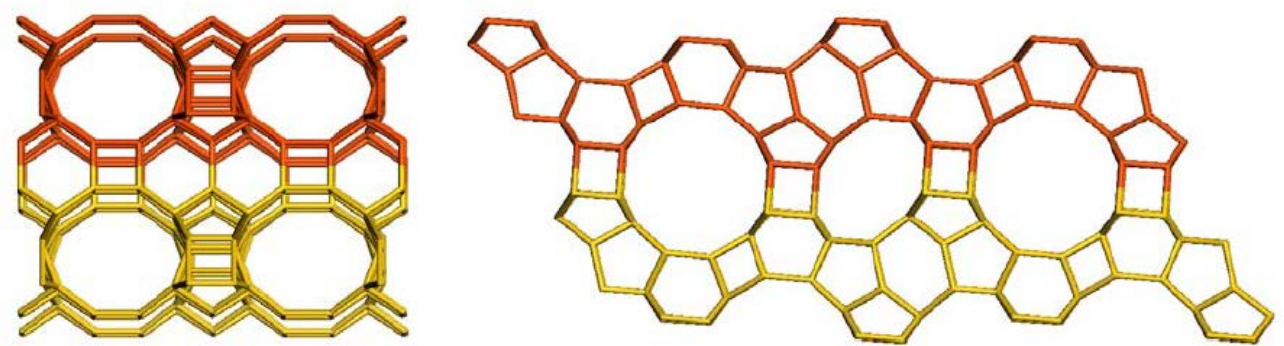
Figure 15: Structure model of IWW (left) and ITQ-38 (right) viewed along the [010] direction. IWW contains 8- and 12-rings and ITQ-38 contains 6-, 10- and 12-rings along the b-axis.
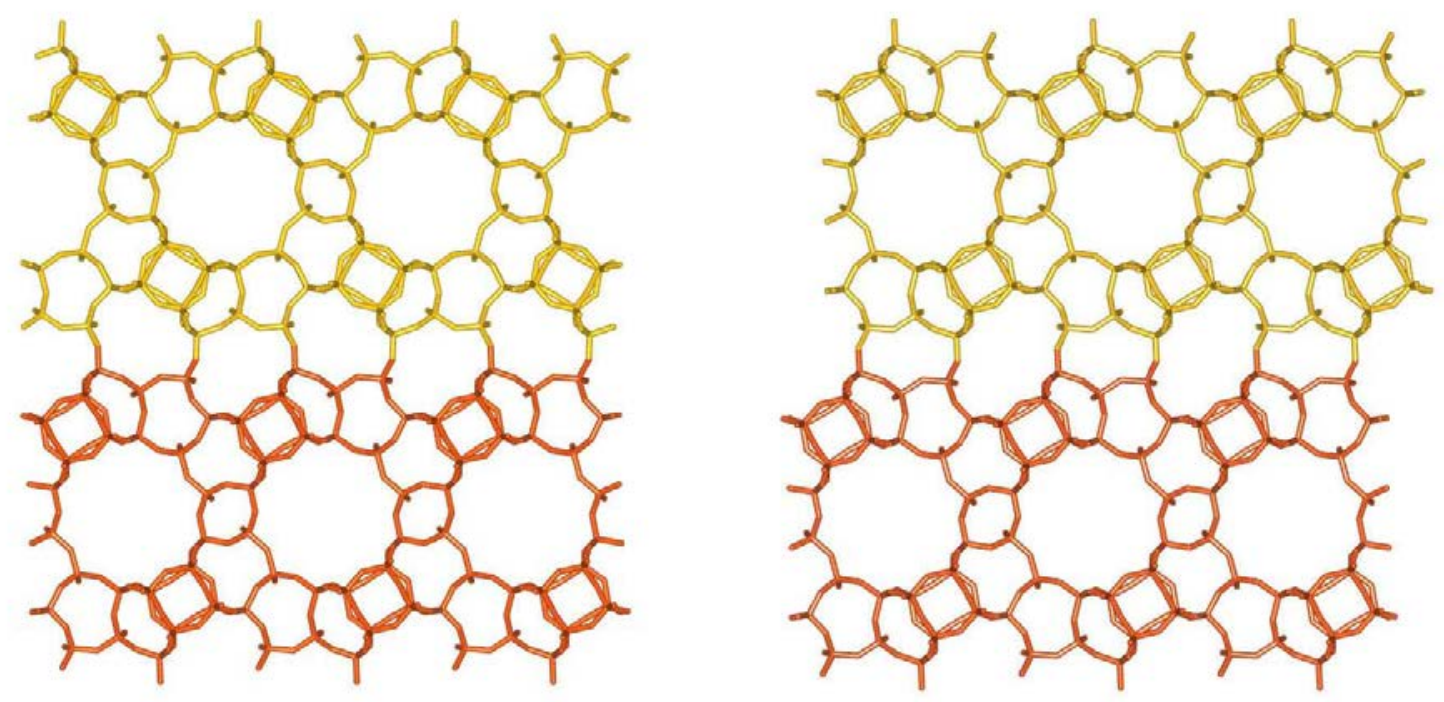
Figure 16: Lattice filtered HRTEM image recorded along the [010] direction.

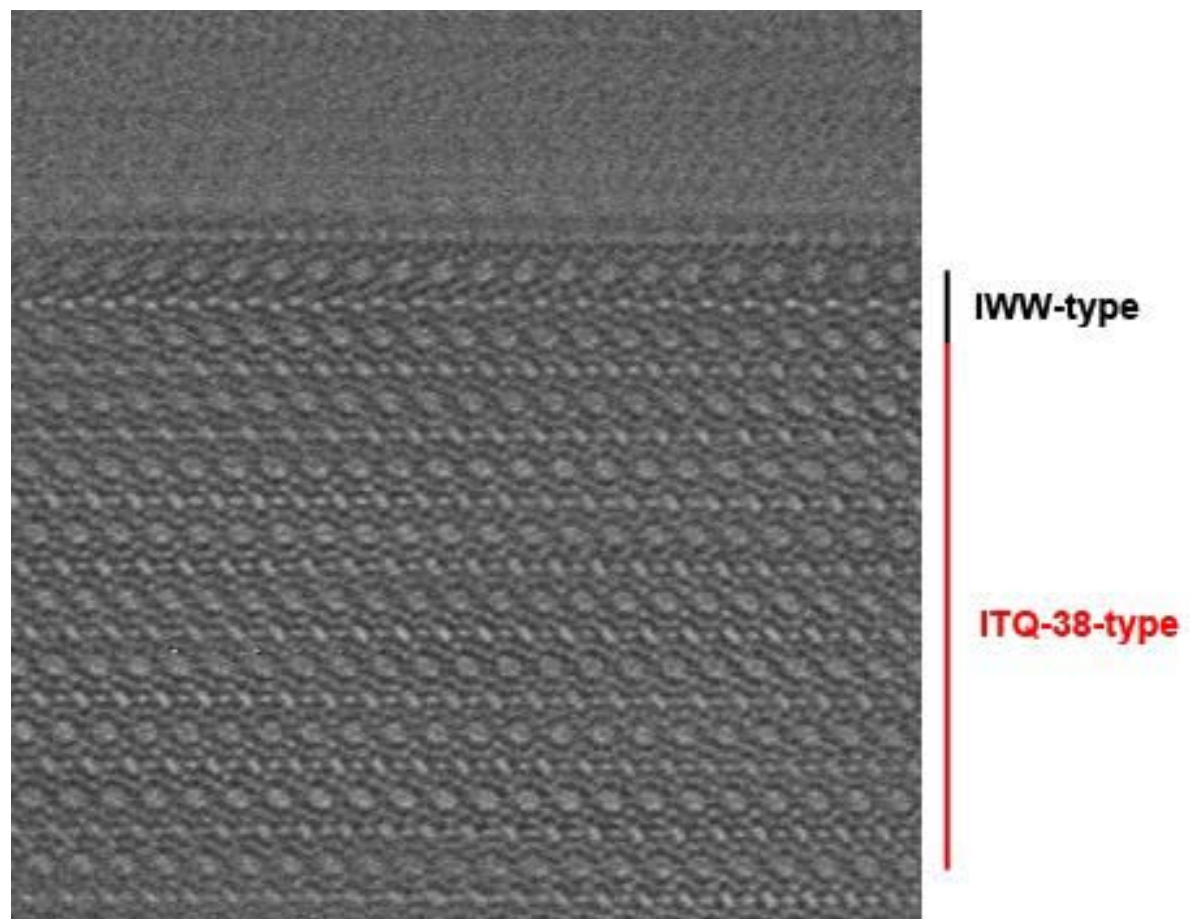


Figure 17: Experimental (bottom) and simulated (top) XRPD patterns of ITQ-38

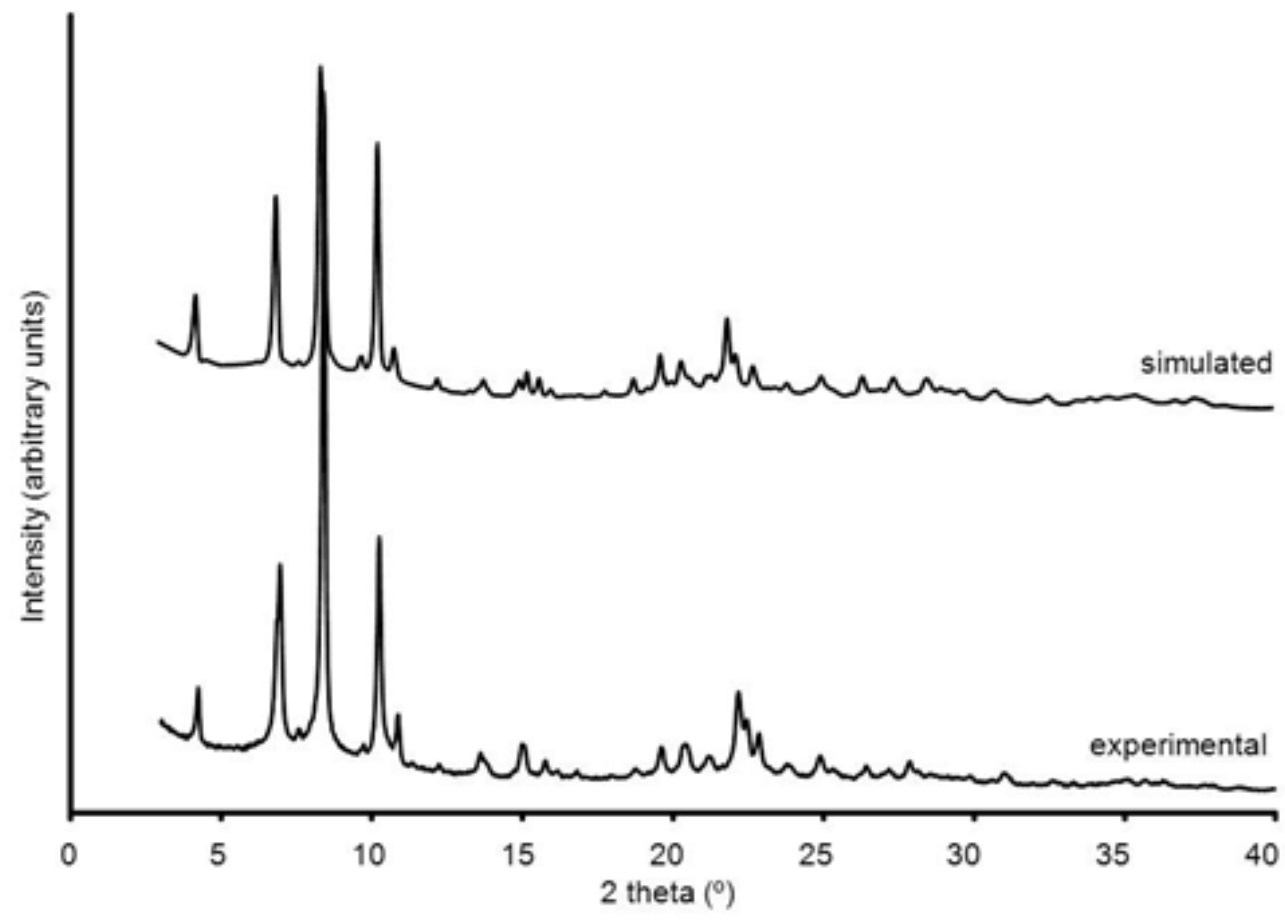


Figure 18: Structure models of ITQ-38 (left) and ITQ-39c (right) viewed along the [100] direction.
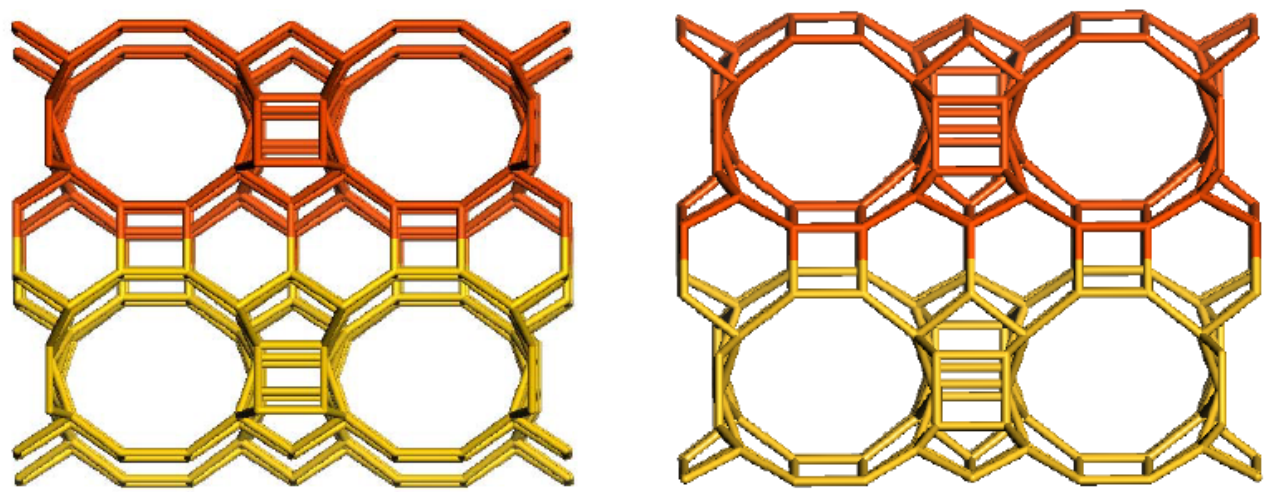
Figure 19: Structure models of ITQ-38 (top) and ITQ-39c (bottom) viewed along the [010] direction.
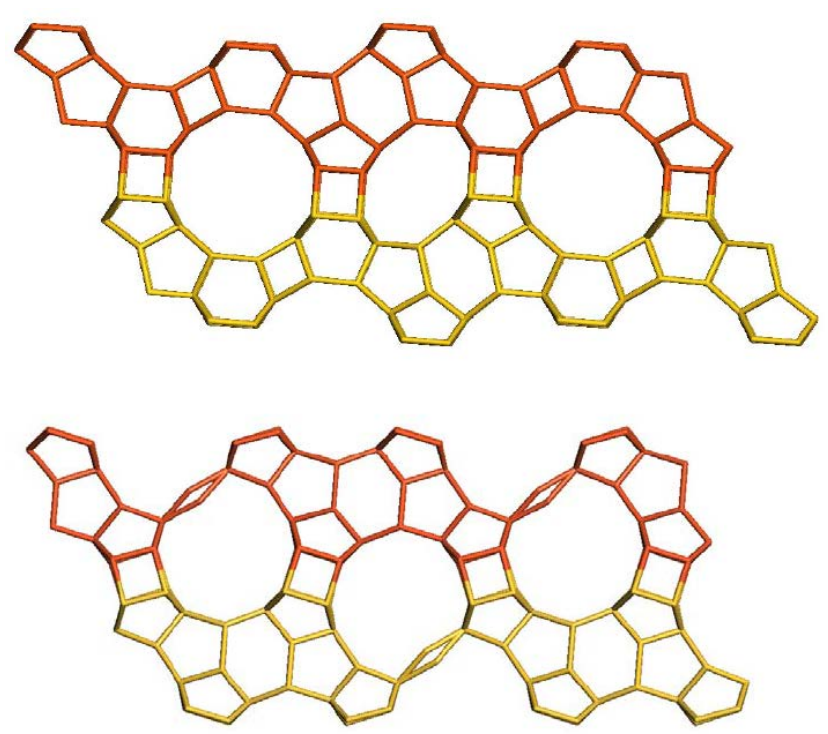
Figure 20: Common building unit (C) with connections shown in yellow for ITQ-38 and ITQ39c (A and B, respectively). Different connecting units for ITQ-38 (D right) and ITQ-39c (D left).

A)
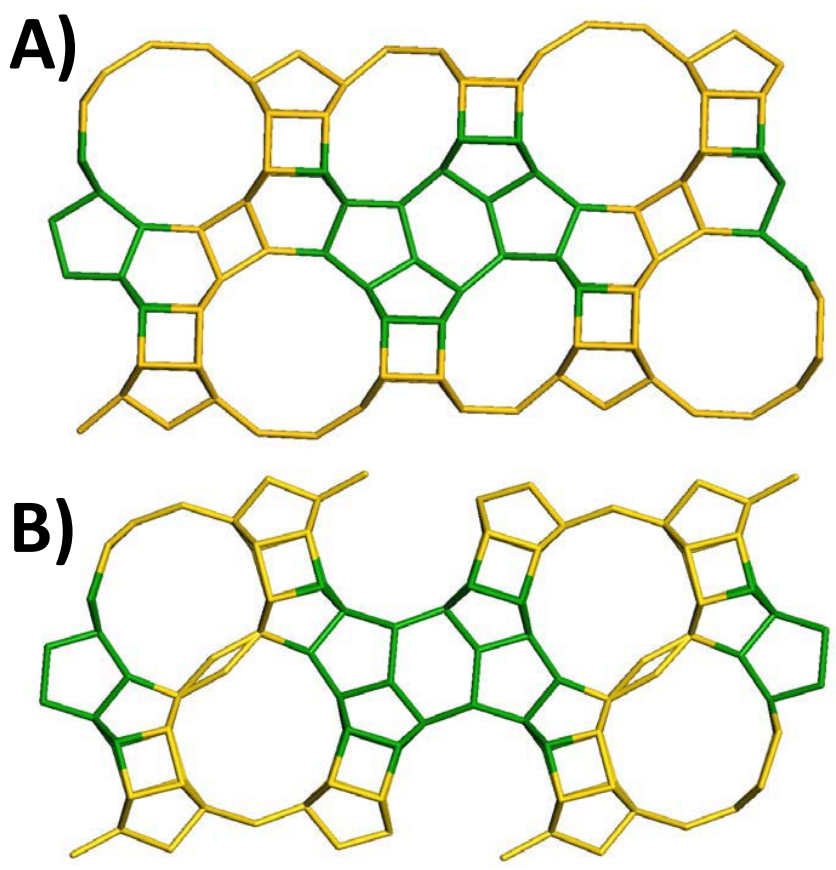

C)

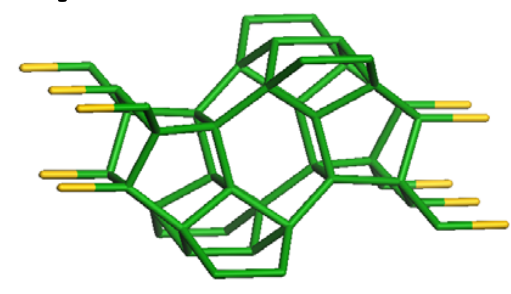

D)

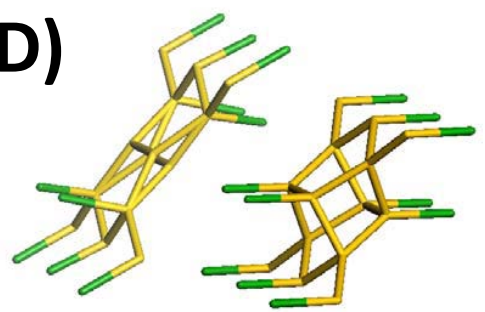




\section{Tables:}

Table 1: Experimental designs for the study of OSDA1 and OSDA2 in fluoride media

\begin{tabular}{ccccc}
\hline \multicolumn{5}{c}{ OSDA1 in F media } \\
\hline Variables & Levels & Level 1 & Level 2 & Level 3 \\
\hline $\mathrm{Si} / \mathrm{Ge}$ & 3 & 5 & 15 & 25 \\
$\mathrm{~T}^{\prime \prime \prime} /(\mathrm{Si}+\mathrm{Ge})$ & 2 & $\mathrm{Al}=0.02$ & $\mathrm{~B}=0.02$ & \\
$\mathrm{H}_{2} \mathrm{O} /(\mathrm{Si}+\mathrm{Ge})$ & 2 & 10 & 20 & \\
\hline
\end{tabular}

\begin{tabular}{ccccc}
\hline \multicolumn{5}{c}{ OSDA2 in F media } \\
\hline Variables & Levels & Level 1 & Level 2 & Level 3 \\
\hline $\mathrm{Si} / \mathrm{Ge}$ & 3 & 2 & 5 & 15 \\
$\mathrm{~T}^{\prime \prime \prime} /(\mathrm{Si}+\mathrm{Ge})$ & 3 & 0 & $\mathrm{Al}=0.033$ & $\mathrm{~B}=0.033$ \\
$\mathrm{H}_{2} \mathrm{O} /(\mathrm{Si}+\mathrm{Ge})$ & 2 & 3 & 10 & \\
\hline
\end{tabular}


Table 2: Experimental designs for the study of OSDA1 and OSDA2 in alkaline media

\begin{tabular}{cccccc}
\hline \multicolumn{5}{c}{ OSDA1 and OSDA2 in OH media } \\
\hline Variables & Levels & Level 1 & Level 2 & Level 3 & Level 4 \\
\hline $\mathrm{Si} / \mathrm{Ge}$ & 3 & 2 & 5 & $\infty$ & \\
$\mathrm{T}^{\prime \prime \prime} /(\mathrm{Si}+\mathrm{Ge})$ & 4 & $\mathrm{Al}=0.02$ & $\mathrm{Al}=0.05$ & $\mathrm{~B}=0.02$ & $\mathrm{~B}=0.05$ \\
$\mathrm{H}_{2} \mathrm{O} /(\mathrm{Si}+\mathrm{Ge})$ & 2 & 3 & 10 & & \\
\hline
\end{tabular}


Table 3: Experimental design using OSDA1 in alkaline media for the ITQ-38 optimization

\begin{tabular}{cccccc}
\hline \multicolumn{5}{c}{ OSDA1 in OH media } \\
\hline Variables & Levels & Level 1 & Level 2 & Level 3 & Level 4 \\
\hline $\mathrm{Si} / \mathrm{Ge}$ & 3 & 5 & 10 & 15 & \\
$\mathrm{~T}^{\prime \prime \prime} /(\mathrm{Si}+\mathrm{Ge})$ & 4 & $\mathrm{Al}=0.02$ & $\mathrm{Al}=0.05$ & $\mathrm{~B}=0.02$ & $\mathrm{~B}=0.05$ \\
$\mathrm{H} \mathrm{O} /(\mathrm{Si}+\mathrm{Ge})$ & 2 & 10 & 20 & & \\
\hline
\end{tabular}


Table 4: Crystallographic data and atomic coordinates of ITQ-38

\begin{tabular}{|c|c|c|c|c|c|c|}
\hline TSite $^{\text {a }}$ & Atom & Occ & $x$ & $\mathrm{y}$ & $\mathrm{z}$ & Wyckoff \\
\hline T1a & $\mathrm{Si}$ & 0.38 & 0.64703 & 0.12165 & 0.23712 & 40 \\
\hline T1b & $\mathrm{Ge}$ & 0.62 & 0.64703 & 0.12165 & 0.23712 & 40 \\
\hline T2a & $\overline{\mathrm{Si}}$ & 0.42 & 0.79443 & 0.12111 & 0.36471 & 40 \\
\hline$T 2 b$ & $\mathrm{Ge}$ & 0.58 & 0.79443 & 0.12111 & 0.36471 & 40 \\
\hline T3a & $\mathrm{Si}$ & 0.52 & 0.98591 & 0.12143 & 0.28969 & 40 \\
\hline T3b & $\mathrm{Ge}$ & 0.48 & 0.98591 & 0.12143 & 0.28969 & 40 \\
\hline T4a & $\mathrm{Si}$ & 0.42 & 0.83884 & 0.12192 & 0.16273 & 40 \\
\hline T4b & $\mathrm{Ge}$ & 0.58 & 0.83884 & 0.12192 & 0.16273 & 40 \\
\hline T5a & $\mathrm{Si}$ & 0.95 & 0.11832 & 0.37892 & 0.06206 & 40 \\
\hline T5b & $\mathrm{Ge}$ & 0.05 & 0.11832 & 0.37892 & 0.06206 & 40 \\
\hline T6a & $\mathrm{Si}$ & 0.92 & 0.26948 & 0.37903 & 0.18720 & 40 \\
\hline T6b & $\mathrm{Ge}$ & 0.08 & 0.26948 & 0.37903 & 0.18720 & 40 \\
\hline T7a & $\mathrm{Si}$ & 1.00 & 0.14545 & 0.30596 & 0.29765 & 40 \\
\hline T8a & $\mathrm{Si}$ & 1.00 & 0.28643 & 0.38010 & 0.41782 & 40 \\
\hline T9a & $\mathrm{Si}$ & 0.89 & 0.51188 & 0.37996 & 0.38103 & 40 \\
\hline T9b & $\mathrm{Ge}$ & 0.11 & 0.51188 & 0.37996 & 0.38103 & 40 \\
\hline T10a & $\mathrm{Si}$ & 0.91 & 0.73330 & 0.30835 & 0.44374 & 40 \\
\hline T10b & $\mathrm{Ge}$ & 0.09 & 0.73330 & 0.30835 & 0.44374 & 40 \\
\hline T11 & $\mathrm{Si}$ & 1.00 & 0.78961 & $1 / 2$ & 0.36424 & $2 n$ \\
\hline T12 & $\mathrm{Si}$ & 1.00 & 0.99119 & $1 / 2$ & 0.28452 & $2 n$ \\
\hline T13 & $\mathrm{Si}$ & 1.00 & 0.84740 & $1 / 2$ & 0.16180 & $2 n$ \\
\hline T14 & $\mathrm{Si}$ & 1.00 & 0.64578 & $1 / 2$ & 0.24148 & $2 n$ \\
\hline T15a & $\mathrm{Si}$ & 0.91 & 0.49530 & 0.30838 & 0.23954 & 40 \\
\hline T15b & $\mathrm{Ge}$ & 0.09 & 0.49530 & 0.30838 & 0.23954 & 40 \\
\hline T16a & $\mathrm{Si}$ & 0.90 & 0.89531 & 0.30710 & 0.07835 & 40 \\
\hline T16b & $\mathrm{Ge}$ & 0.10 & 0.89531 & 0.30710 & 0.07835 & 40 \\
\hline 01 & 0 & 1 & 0.02161 & 0.32049 & 0.09081 & 40 \\
\hline $\mathrm{O} 2$ & 0 & 1 & 0.08782 & $1 / 2$ & 0.04700 & $2 n$ \\
\hline $\mathrm{O3}$ & 0 & 1 & 0.22232 & 0.37389 & 0.11293 & 40 \\
\hline 04 & 0 & 1 & 0.27962 & $1 / 2$ & 0.20975 & $2 n$ \\
\hline 05 & 0 & 1 & 0.38395 & 0.32394 & 0.19639 & 40 \\
\hline 06 & 0 & 1 & 0.19091 & 0.31738 & 0.22939 & 40 \\
\hline 07 & 0 & 1 & 0.09060 & 0.19259 & 0.30260 & 40 \\
\hline 08 & 0 & 1 & 0.05949 & 0.39664 & 0.30504 & 40 \\
\hline 09 & 0 & 1 & 0.24075 & 0.31723 & 0.35422 & 40 \\
\hline 010 & 0 & 1 & 0.24731 & 0.32401 & 0.47981 & 40 \\
\hline 011 & 0 & 1 & 0.24540 & $1 / 2$ & 0.41356 & $2 n$ \\
\hline 012 & 0 & 1 & 0.41352 & 0.37914 & 0.42321 & 40 \\
\hline 013 & 0 & 1 & 0.47897 & 0.32043 & 0.31415 & 40 \\
\hline 014 & 0 & 1 & 0.54410 & $1 / 2$ & 0.36812 & $2 n$ \\
\hline 015 & 0 & 1 & 0.60930 & 0.31888 & 0.42000 & 40 \\
\hline 016 & 0 & 1 & 0.77493 & 0.19401 & 0.42503 & 40 \\
\hline 017 & 0 & 1 & 0.79723 & 0.39685 & 0.40894 & 40 \\
\hline 018 & 0 & 1 & 0.68044 & $1 / 2$ & 0.31761 & $2 n$ \\
\hline 019 & 0 & 1 & 0.88643 & $1 / 2$ & 0.32100 & $2 n$ \\
\hline O20 & 0 & 1 & 0.95661 & $1 / 2$ & 0.20839 & $2 n$ \\
\hline 021 & 0 & 1 & 0.83975 & 0.39664 & 0.11731 & 40 \\
\hline
\end{tabular}




\begin{tabular}{|l|l|l|l|l|l|l|}
\hline 022 & 0 & 1 & 0.75055 & $1 / 2$ & 0.20503 & $2 \mathrm{n}$ \\
\hline 023 & 0 & 1 & 0.57714 & 0.39681 & 0.22090 & $4 \mathrm{o}$ \\
\hline 024 & 0 & 1 & 0.54292 & 0.19413 & 0.22612 & $4 \mathrm{o}$ \\
\hline 025 & 0 & 1 & 0.61271 & 0 & 0.23993 & $2 \mathrm{~m}$ \\
\hline 026 & 0 & 1 & 0.71961 & 0.13843 & 0.17971 & $4 \mathrm{o}$ \\
\hline 027 & 0 & 1 & 0.71321 & 0.15432 & 0.30390 & $4 \mathrm{o}$ \\
\hline 028 & 0 & 1 & 0.77501 & 0 & 0.38251 & $2 \mathrm{~m}$ \\
\hline 029 & 0 & 1 & 0.91371 & 0.13579 & 0.34747 & $4 \mathrm{o}$ \\
\hline 030 & 0 & 1 & 0.91988 & 0.15649 & 0.22335 & $4 \mathrm{o}$ \\
\hline 031 & 0 & 1 & 0.85730 & 0 & 0.14646 & $2 \mathrm{~m}$ \\
\hline 032 & 0 & 1 & 0.86025 & 0.19319 & 0.10205 & $4 \mathrm{o}$ \\
\hline 033 & 0 & 1 & 0.85820 & 0.32059 & 0.00300 & $4 \mathrm{o}$ \\
\hline 034 & 0 & 1 & 0.02006 & 0 & 0.28498 & $2 \mathrm{~m}$ \\
\hline
\end{tabular}

${ }^{a}$ Sites where Ge isomorphically replaces $\mathrm{Si}$ are splited in two sites, $\mathrm{a}$ and $\mathrm{b}$, with identical coordinates, being the sum of their respective occupancies equal to 1 .

Refined cell parameters: $a=12.9216(17) \AA, b=12.9390(16) \AA, c=21.348(3) \AA, \beta=96.799(9)^{\circ}$, $V=3544.0(8) \AA^{3}$; Space group: P $2 / m$ (No. 10)

Cell composition: $\mathrm{Si}_{44.88} \mathrm{Ge}_{11.12} \mathrm{O}_{112}$; chemical composition: $\mathrm{Si}_{0.8} \mathrm{Ge}_{0.2} \mathrm{O}_{2}, \mathrm{Z}=56$

Calculated density: $1.81 \mathrm{~g} / \mathrm{cm}^{3}$; crystallographic density: $15.8 \mathrm{TO}_{2} / 1000 \AA^{3}$; crystallographic experimental density: $15.9 \mathrm{TO}_{2} / 1000 \AA^{3}$ 


\section{References:}

(1) http://www.iza-online.org/.

(2) Davis, M. E. Nature 2002, 417, 813.

(3) (a) Corma, A. Chem. Rev. 1997, 97, 2373; (b) Auerbach, S. M., Carrado, K. A. Dutta, P. K. (eds) Handbook of Zeolite Science and Technology (Marcel Dekker, New York, 2004).

(4) (a) Clark, L. A.; Ye, G. T.; Snurr, R. Q. Phys. Rev. Lett. 2000, 84, 2893; (b) Kärger, J.; Ruthven, D. M. Diffusion in Zeolites and Other Microporous Solids (Wiley, New York, 1992).

(5) (a) Paillaud, J. L.; Harbuzaru, B.; Patarin, J.; Bats, N. Science 2004, 304, 990; (b) Corma, A.; Diaz-Cabanas, M. J.; Rey, F.; Nicolopoulus, S.; Boulahya, K. Chem. Commun. 2004, 12, 1356.

(6) Corma, A.; Diaz-Cabañas, M. J.; Jorda, J. L.; Martinez, C.; Moliner, M. Nature 2006, 443, 842. (7) (a) Lobo, R. F.; Pan, M.; Chan, I.; Li, H.; Medrud, R. C.; Zones, S. I.; Crozier, P. A.; Davis, M. E. Science 1993, 262, 1543; (b) Dorset, D. L.; Weston, S. C.; Dhingra, S. S. J. Phys. Chem. B 2006, 110, 2045; (c) Lobo, R. F.; Davis, M. E. J. Am. Chem. Soc. 1995, 117, 3766; (d) Corma, A.; Rey, F.; Valencia, S.; Jordá, J. L.; Rius, J. Nat. Mater. 2003, 2, 493; (e) Simancas, R.; Dari, D.; Velamazán, N.; Navarro, M. T.; Cantín, A.; Jordá, J. L.; Sastre, G.; Corma, A.; Rey, F. Science, 2010, 330, 1219.

(8) Willhammar, T.; Sun, J.; Wan, W; Oleynikov, P.; Zhang, D.; Zou, X.; Moliner, M.; Gonzalez, J.; Martínez, C; Rey, F.; Corma, A. "Structure and catalytic properties of the most complex intergrown zeolite ITQ-39 determined by electron crystallography", Submitted to Nat. Chem.

(9) Moliner, M.; González, J.; Portilla, M. T.; Willhammar, T.; Rey, F.; Llopis, F. J.; Zou, X.; Corma A. J. Am. Chem. Soc. 2011, 133, 9497.

(10) (a) O'Keefe, M.; Yaghi, O. M. Chem. Eur. J., 1999, 5, 2796; (b) Villaescusa, L. A.; Lighfoot, P.; Morris, R. E. Chem. Commun., 2002, 19, 2220; (c) Blasco, T.; Corma, A.; Díaz-Cabañas, M. J.; Rey, F.; Vidal-Moya, J. A.; Zicovich-Wilson, C. M. J. Phys. Chem. B, 2002, 106, 2637; (d) Sun, J; Bonneau, C.; Cantín, A; Corma, A.; Diaz-Cabañas, M. J.; Moliner, M.; Zhang, D.; Li, M.; Zou, X. Nature., 2009, 458, 1154.

(11) Newsam J. M.; Treacy M. M. J.; Koetsier W. T.; de Gruyter C. B. Proc. R. Soc. Lond. A., 1988, $420,375$.

(12) Lobo, R. F.; Pan, M.; Chan, I.; Medrud, R. C.; Zones, S. I.; Crozier, P. A.; Davis, M. E. J. Phys. Chem. 1994, 98, 12040.

(13) (a) Corma, A.; Navarro, M. T.; Rey, F.; Rius, J.; Valencia, S. Angew. Chem., Int. Ed., 2001, 40, 2277; (b) Castaneda, R.; Corma, A.; Fornes, V.; Rey, F.; Rius, J. J. Am. Chem. Soc., 2003, 125, 7820.

(14) Corma, A.; Davis, M. E. ChemPhysChem., 2004, 5, 304.

(15) (a) Kessler, H. Mater. Res. Soc. Symp. Proc., 1991, 233, 47; (b) Barret, P. A.; Camblor, M. A.; Corma. A.; Jones, R. H.; Villaescusa, L. A. J. Phys. Chem. B., 1998, 102, 4147; (c) Zones, S. I.; Burton, A. W.; Lee, G. S.; Olmstead, M. M. J. Am. Chem. Soc., 2007, 129, 9066; (d) Cantin, A.; Corma, A.; Díaz-Cabañas, M. J.; Jorda, J. L.; Moliner, M.; Rey, F. Angew. Chem. Int. Ed., 2006, 45, 8013; (e) Cantin, A.; Corma, A.; Diaz-Cabanas, M. J.; Jorda, J. L.; Moliner, M. J. Am. Chem. Soc., 2006, 128, 4216.

(16) Koller, H.; Wolker, A.; Eckert, H.; Panz, C.; Behrens, P. Angew. Chem., Int. Ed. 1997, 36, 2823.

(17) Zones, S. I.; Hwang, S-J.; Elomari, S.; Ogino, I., Davis, M. E.; Burton, A. W. Comp. Rend. Chim., 2005, 8, 267.

(18) Zones, S. I.; Hwang, S-J. Micropor. Mesopor. Mater., 2003, 58, 263.

(19) Werner, P. E.; Eriksson, L.; Westdahl, M.J.; Appl. Crystallogr., 1985, 18, 367

(20) (a) DeRosier, D. J.; Klug, A. Nature, 1968, 217, 130; (b) Hovmöller, S.; Sjögren, A.; Farrants, G.; Sundberg, M.; Marinder, B. O. Nature, 1984, 311, 238. 
(21) (a) Gramm, F. et al. Nature, 2006, 444, 79; (b) Baerlocher, Ch. et al. Science, 2007, 315, 1113; (c) Baerlocher, Ch. et al. Nature Mater. 2008, 7, 631; (d) Sun, J. L. et al. Nature, 2009, 458, 1154; (e) Jiang, J.-X. et al. Science, 2011, 333, 1331.

(22) Rodriguez-Carvajal, J.; Comm. Powder Diffr. (IUCr) Newslett., 2001, 26, 12 